\title{
Acidithiobacillus ferrooxidans metabolism: from genome sequence to industrial applications
} Jorge Valdés ${ }^{1}$, Inti Pedroso ${ }^{1}$, Raquel Quatrini' ${ }^{1}$, Robert J Dodson ${ }^{2}$, Herve Tettelin $^{2,3}$, Robert Blake II $^{6}$, Jonathan A Eisen ${ }^{2,4,5}$ and David S Holmes*1

\author{
Address: ${ }^{1}$ Center for Bioinformatics and Genome Biology, Fundación Ciencia para la Vida and Depto. de Ciencias Biologicas, Facultad de Ciencias \\ de la Salud, Universidad Andres Bello, Santiago Chile, ${ }^{2}$. Craig Venter Institute, Rockville, MD, USA, ${ }^{3}$ The Institute for Genomic Sciences, \\ University of Maryland, Baltimore, MD, USA, ${ }^{4}$ University of California Davis Genome Center, Section of Evolution and Ecology, U.C. Davis, Davis, \\ CA, USA, ${ }^{5}$ University of California Davis Genome Center, Dept of Medical Microbiology and Immunology, U.C. Davis, Davis, CA, USA and \\ ${ }^{6}$ Division of Basic Pharmaceutical Sciences, Xavier University, New Orleans, LA, USA \\ Email: Jorge Valdés - jorge.valdes@gmail.com; Inti Pedroso - inti.pedroso@gmail.com; Raquel Quatrini - rquatrini@yahoo.com.ar; \\ Robert J Dodson - rjdodson@jcvi.org; Herve Tettelin - tettelin@som.umaryland.edu; Robert Blake - rblake@xula.edu; \\ Jonathan A Eisen - jaeisen@ucdavis.edu; David S Holmes* - dsholmes2000@yahoo.com \\ * Corresponding author
}

Published: II December 2008

BMC Genomics 2008, 9:597 doi:10.1 186/1471-2164-9-597

This article is available from: http://www.biomedcentral.com/147/-2/64/9/597

(C) 2008 Valdés et al; licensee BioMed Central Ltd.

This is an Open Access article distributed under the terms of the Creative Commons Attribution License (http://creativecommons.org/licenses/by/2.0), which permits unrestricted use, distribution, and reproduction in any medium, provided the original work is properly cited.

\begin{abstract}
Background: Acidithiobacillus ferrooxidans is a major participant in consortia of microorganisms used for the industrial recovery of copper (bioleaching or biomining). It is a chemolithoautrophic, $\gamma$-proteobacterium using energy from the oxidation of iron- and sulfur-containing minerals for growth. It thrives at extremely low $\mathrm{pH}(\mathrm{pH} \mathrm{I}-2)$ and fixes both carbon and nitrogen from the atmosphere. It solubilizes copper and other metals from rocks and plays an important role in nutrient and metal biogeochemical cycling in acid environments. The lack of a well-developed system for genetic manipulation has prevented thorough exploration of its physiology. Also, confusion has been caused by prior metabolic models constructed based upon the examination of multiple, and sometimes distantly related, strains of the microorganism.
\end{abstract}

Results: The genome of the type strain A. ferrooxidans ATCC 23270 was sequenced and annotated to identify general features and provide a framework for in silico metabolic reconstruction. Earlier models of iron and sulfur oxidation, biofilm formation, quorum sensing, inorganic ion uptake, and amino acid metabolism are confirmed and extended. Initial models are presented for central carbon metabolism, anaerobic metabolism (including sulfur reduction, hydrogen metabolism and nitrogen fixation), stress responses, DNA repair, and metal and toxic compound fluxes.

Conclusion: Bioinformatics analysis provides a valuable platform for gene discovery and functional prediction that helps explain the activity of $A$. ferrooxidans in industrial bioleaching and its role as a primary producer in acidic environments. An analysis of the genome of the type strain provides a coherent view of its gene content and metabolic potential. 


\section{Background}

Acidithiobacillus ferrooxidans is a Gram-negative, $\gamma$-proteobacterium that thrives optimally at $30^{\circ} \mathrm{C}$ and $\mathrm{pH} 2$, but can grow at $\mathrm{pH} 1$ or lower [1]. It is abundant in natural environments associated with pyritic ore bodies, coal deposits, and their acidified drainages [2,3]. It is an important member of microbial consortia used to recover copper via a process known as bioleaching or biomining [4].

In a typical bioleaching operation, copper ore is first pulverized and placed in heaps. The heaps are then sprinkled with sulfuric acid and aerated to promote the microbial oxidation of iron and sulfur compounds. Some bioleaching heaps are very extensive; for example, the Escondida mine in northern Chile is putting into operation a heap that is $5 \mathrm{~km}$ long by $2 \mathrm{~km}$ wide and $126 \mathrm{~m}$ high (David Dew, personal communication). With a volume of a little more than one trillion $\left(10^{12}\right)$ liters, this bioleaching heap is arguably the world's largest industrial bioreactor.

Bioleaching of copper ores is a two-step process: first, the biological oxidation of Fe(II) to produce Fe(III); second, the chemical oxidation of $\mathrm{Cu}(\mathrm{I})$ to the more soluble $\mathrm{Cu}(\mathrm{II})$ by $\mathrm{Fe}$ (III) which is reduced to $\mathrm{Fe}(\mathrm{II})$ in the process. A. ferrooxidans plays a key role by reoxidizing the $\mathrm{Fe}$ (II) to $\mathrm{Fe}(\mathrm{III})$, thus completing the cycle and allowing bioleaching to continue (Figure 1). The sulfuric acid produced by the biological oxidation of reduced sulfur compounds also promotes the solubilization of the $\mathrm{Cu}(\mathrm{II})$. Copper is recovered from this acidic solution using physico-chemical technologies such as solvent extraction and electroplating.

Bioleaching accounts for $10 \%$ of the copper production worldwide and is especially important as a technology for ores with a low percentage of copper that are otherwise uneconomical to extract. Another attractive feature of bioleaching is that it does not produce pollutants such as sulfur dioxide and arsenic that result from smelting. However, bioleaching does generate acid mine drainage that must be managed to prevent its release into the environment. The importance of bioleaching is likely to increase in the future as the mineral industry exploits ore deposits with lower copper content as richer ores become depleted. The increasing importance of bioleaching as a biotechnological process is stimulating increasing interest in the biology of $A$. ferrooxidans and associated bioleaching microorganisms.

A. ferrooxidans is one of the few microorganisms known to gain energy by the oxidation of ferrous iron in acidic environments, using the low $\mathrm{pH}$ of its natural environment to generate reverse electron flow from $\mathrm{Fe}(\mathrm{II})$ to NADH [5-8]. It can also obtain energy by the oxidation of reduced sul- fur compounds, hydrogen, and formate $[9,10]$. The microorganism makes an important contribution to the biogeochemical cycling of metals in the environment and has the potential to assist in the remediation of metal contaminated sites by its ability to oxidize and reduce metals. Ferric iron and sulfuric acid are major by-products of its energy-transducing processes, and these chemicals can mobilize metals in the environment including toxic metals such as arsenic [11]. It can also reduce ferric ion and elemental sulfur, thus promoting the recycling of iron and sulfur compounds under anaerobic conditions [12,13]. Since the microorganism can also fix $\mathrm{CO}_{2}$ and nitrogen, it is thought to be a primary producer of carbon and nitrogen in acidic, nutrient-poor environments [14-17].

The study of $A$. ferrooxidans offers exceptional opportunities to probe life in extremely acidic environments. It may also offer insights into ancient ways of life in Archaean, euxinic, acidic seas [18] and suggest potential biomarkers to be used when searching for evidence of extra-terrestrial life [19]. One of its unusual properties is its ability to aerobically oxidize solid substrates such as pyrite $\left(\mathrm{FeS}_{2}\right)$. Since the substrate cannot enter the cell, initial electron removal must take place either within the outer cell membrane or completely outside the cell. Although a substantial body of information exists regarding the use of solid minerals as electron sinks for biological processes (e.g., the reduction of ferric iron [20]), considerably less is known about how microorganisms recognize, attach to, and extract electrons from solid substrates. Investigations into the fundamental interactions between bacteria and mineral surfaces are critical for understanding the intricacies of interfacial biochemistry, biofilm formation, bacterial recognition of mineral surfaces, and the dispersal of microorganisms in the environment.

A. ferrooxidans thrives in mineral rich, acid environments where the concentration of dissolved ferrous iron can be as high as $10^{-1} \mathrm{M}$, about $10^{16}$ times that found in circumneutral environments. The abundance of soluble iron has the potential to pose severe oxidative stress that could lead to DNA and protein damage via the Fenton reaction. This prompts questions as to the mechanisms that $A$. ferrooxidans employs for iron assimilation and homeostasis $[21,22]$ and how it balances its use of iron as both a micronutrient and as a required energy source. In its natural environment, it must also confront unusually severe toxicity due to the high concentration of dissolved metals (e.g., copper, arsenic, mercury).

Although the internal $\mathrm{pH}$ of $A$. ferrooxidans is about $\mathrm{pH}$ 6.5 , proteins that are either wholly or partially outside the inner membrane must function at $\mathrm{pH} 1-2$, raising fundamental questions regarding how they fold and make protein-protein contact when confronted with such an 


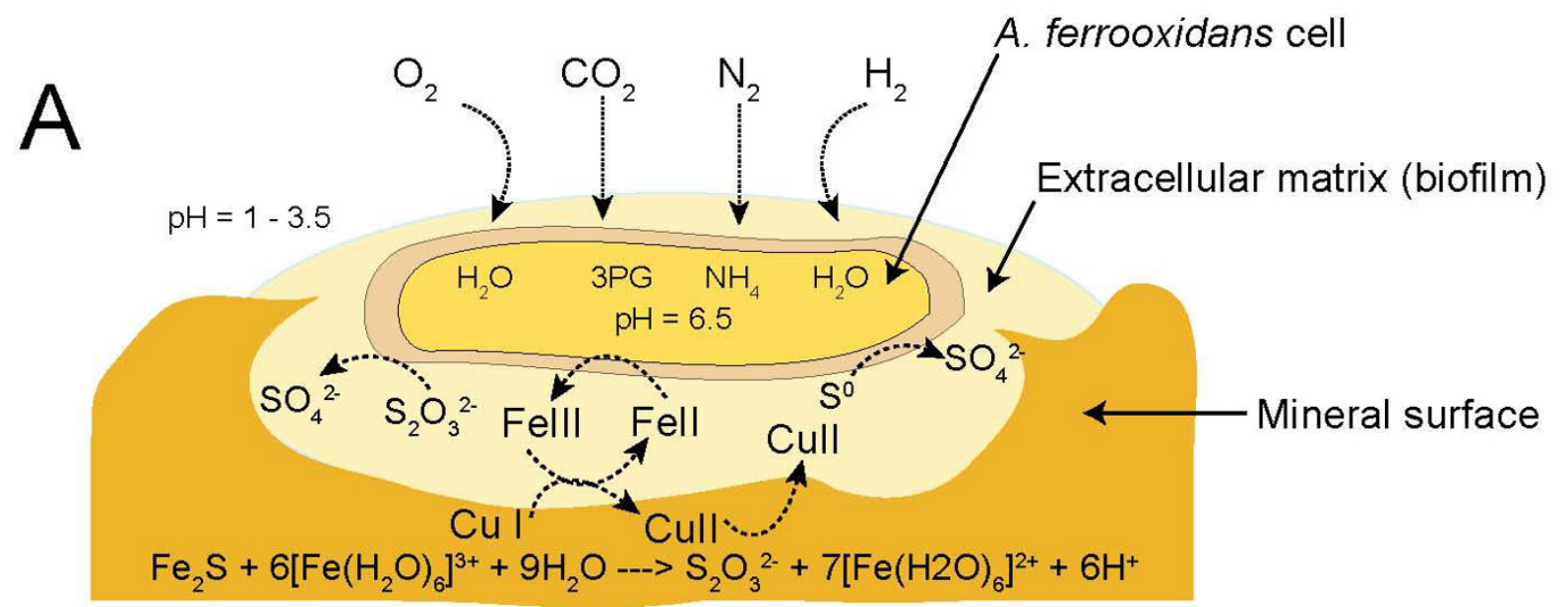

\section{$B$}

\section{Aerobic metabolism:}

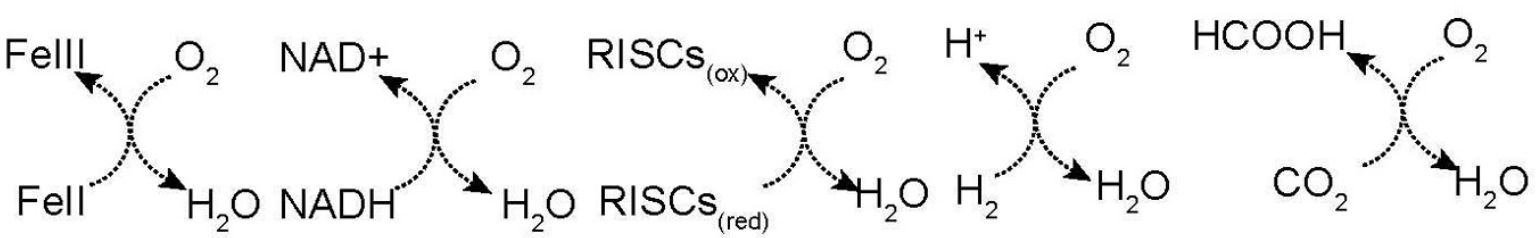

Anaerobic metabolism:

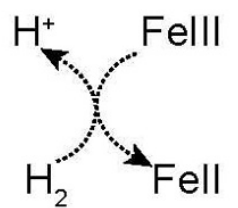

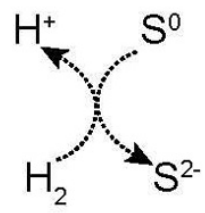

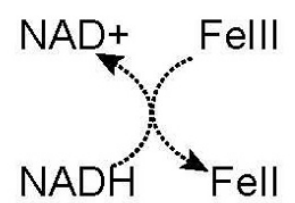

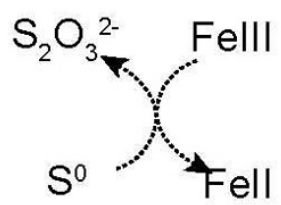

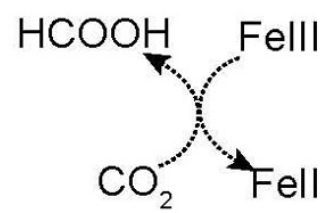<smiles></smiles>
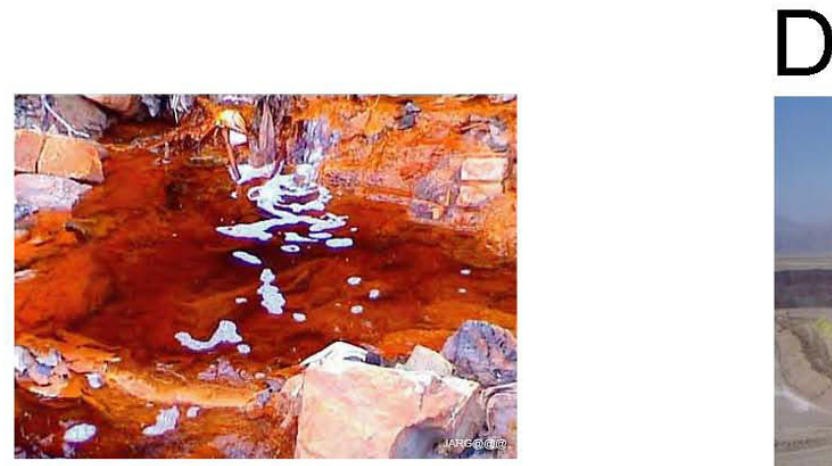

\section{Figure I}

A. ferrooxidans and its proposed role in bioleaching. The chemolithoautotrophic metabolism of $A$. ferrooxidans results in the oxidation/reduction of iron and sulfur compounds and the solubilization of copper and other commercially valuable metals in a process called bioleaching or biomining. It also results in the production of acidified solutions in pristine environments and acid mine drainage in bioleaching operations. A) Model of copper bioleaching by A. ferrooxidans. B) Oxidation/reduction reactions carried out by $A$. ferrooxidans. The scheme provided here presents the basic concepts of bioleaching and further details are provided in the review [4]. C) Acid mine drainage in the Rio Tinto, Spain, derived from naturally occurring pyritic ore bodies and abandoned mine workings initiated in pre-Roman times [3]. D) Commercial bioleaching heap for copper recovery, Chile. 3PG: 3-phosphoglycerate. 
extremely high proton concentration. It also raises questions as to how proton-driven membrane transport and energy processes function in the face of a proton motif force (pmf) across the inner membrane that is several orders of magnitude higher than typically found in neutrophilic environments.

Unfortunately, the lack of a well-developed system for genetic manipulation has prevented thorough exploration of the molecular biology and physiology of A. ferrooxidans. A bioinformatics-based analysis of its genome offers a powerful tool for investigating its metabolism. However, many of the earlier investigations of its genetics and metabolism were carried out on a variety of strains, some of which may be only distantly (or not at all) related to $A$. ferrooxidans. This allows the possibility that some experimental results, including enzyme identifications were not reliable indicators of the metabolism of the species. Genomic analysis of the type strain of $A$. ferrooxidans can provide a more coherent view of the gene content and metabolic potential of the species.

An analysis of amino acid metabolism based on the draft genome sequence of $A$. ferrooxidans ATCC 23270 was previously reported [23]. Here we present a complete, genome-based blueprint of the metabolic and regulatory capabilities of $A$. ferrooxidans and relate these findings to its unique lifestyle. This analysis will add to our understanding of the biochemical pathways that underpin the biogeochemical processes, metabolic functions, and evolution of microbial communities in acidic environments. This information also advances our understanding of the role of $A$. ferrooxidans in industrial bioleaching.

\section{Results and discussion \\ I. Genomic properties}

The genome of A. ferrooxidans ATCC 23270 (type strain) consists of a single circular chromosome of 2,982,397 bp with a $\mathrm{G}+\mathrm{C}$ content of $58.77 \%$. No plasmids were detected in the type strain, although they occur in several other strains of [24]. A total of 3217 protein-coding genes (CDSs) were predicted, of which 2070 (64.3\%) were assigned a putative function (Table 1 and Figure 2). The genome encodes two ribosomal operons and 78 tRNA genes. A putative origin of replication (Figure 2) has been identified from marginal GC skew variations in the genome and by the localization of the $d n a N$ and $d n a A$ genes (AFE0001 and AFE3309).

\section{Chemolithoautotrophy}

A. ferrooxidans has a complete repertoire of genes required for a free-living, chemolithoautotrophic lifestyle, including those for $\mathrm{CO}_{2}$ fixation and nucleotide and cofactor biosynthesis (Additional file 1). Analysis of an earlier draft genome had predicted genes for the pathways for synthesis of most amino acids, although ten genes were missing [23]. Seven of these missing assignments have now been detected: a potential 6-phosphofructokinase in the glycolysis pathway (EC 2.7.1.11; AFE1807), pyruvate dehydrogenase (EC 1.2.4.1; AFE3068-70); shikimate kinase in the chorismate synthesis pathway and required for tryptophan, phenylalanine and tyrosine biosynthesis (EC 2.7.1.71; AFE0734); homeserine kinase in the threonine biosynthesis pathway (EC 2.7.1.39; AFE3097); Nacetyl-gamma-glutamil-1-phosphate reductase in the ornithine biosynthesis pathway and required for proline biosynthesis (EC 1.2.1.38; AFE3073); pirroline-5-carboxilate reductase involved in proline biosynthesis (EC 1.5.1.2; AFE0262); and asparagine synthase (EC 6.3.5.4: AFE1353). The three genes identified in E. coli which have not been found in A. ferrooxidans encode ornithine cyclodeaminase (EC 4.3.1.12) involved in proline biosynthesis, aromatic-amino-acid transaminase (EC 2.6.1.57), and arogenate dehydrogenase involved in tyrosine biosynthesis (EC 1.3.1.43).

A. ferrooxidans has two glutamyl-tRNA synthetases: a more discriminating one (D-GluRS, AFE0422) that charges only Glu-tRNA(Glu) and a less discriminating one (ND-GluRS, AFE2222) that charges Glu-tRNA(Glu) and GlutRNA(Gln). The latter one is a required intermediate in protein synthesis in many organisms [25]. An indirect regulation of glutamyl-tRNA synthetase by heme status suggests a potential metabolic connection between heme requirements, nitrogen, and central carbon metabolism [26].

Bioinformatic analysis supports prior experimental evidence that $A$. ferrooxidans has a versatile aerobic metabolism, capable of providing energy and reducing power requirements from inorganic compounds by the oxidation of $\mathrm{Fe}(\mathrm{II})$, reduced sulfur compounds, formate, and hydrogen. In addition, gene function predictions suggest that the microorganism is capable of anaerobic or microaerophilic growth using $\mathrm{Fe}$ (III) or elemental sulfur as alternative electron acceptors [27]. Many of the predictions were experimentally validated in a piece-meal fashion in a number of diverse strains of $A$. ferrooxidans, some of which may not belong to the same species [28]. Herein, we describe a coherent view of the metabolic potential of the type strain that will now allow a systematic appraisal of the diversity of the metabolic capacity of the A. ferrooxidans pangenome.

\section{I $\mathrm{CO}_{2}$ fixation}

A. ferrooxidans fixes $\mathrm{CO}_{2}$ via the Calvin-Benson-Bassham reductive pentose phosphate cycle (Calvin cycle) using energy and reducing power derived from the oxidation of iron or sulfur [29]. Early studies showed a relationship between the rate of iron and sulfur oxidation and the rate 


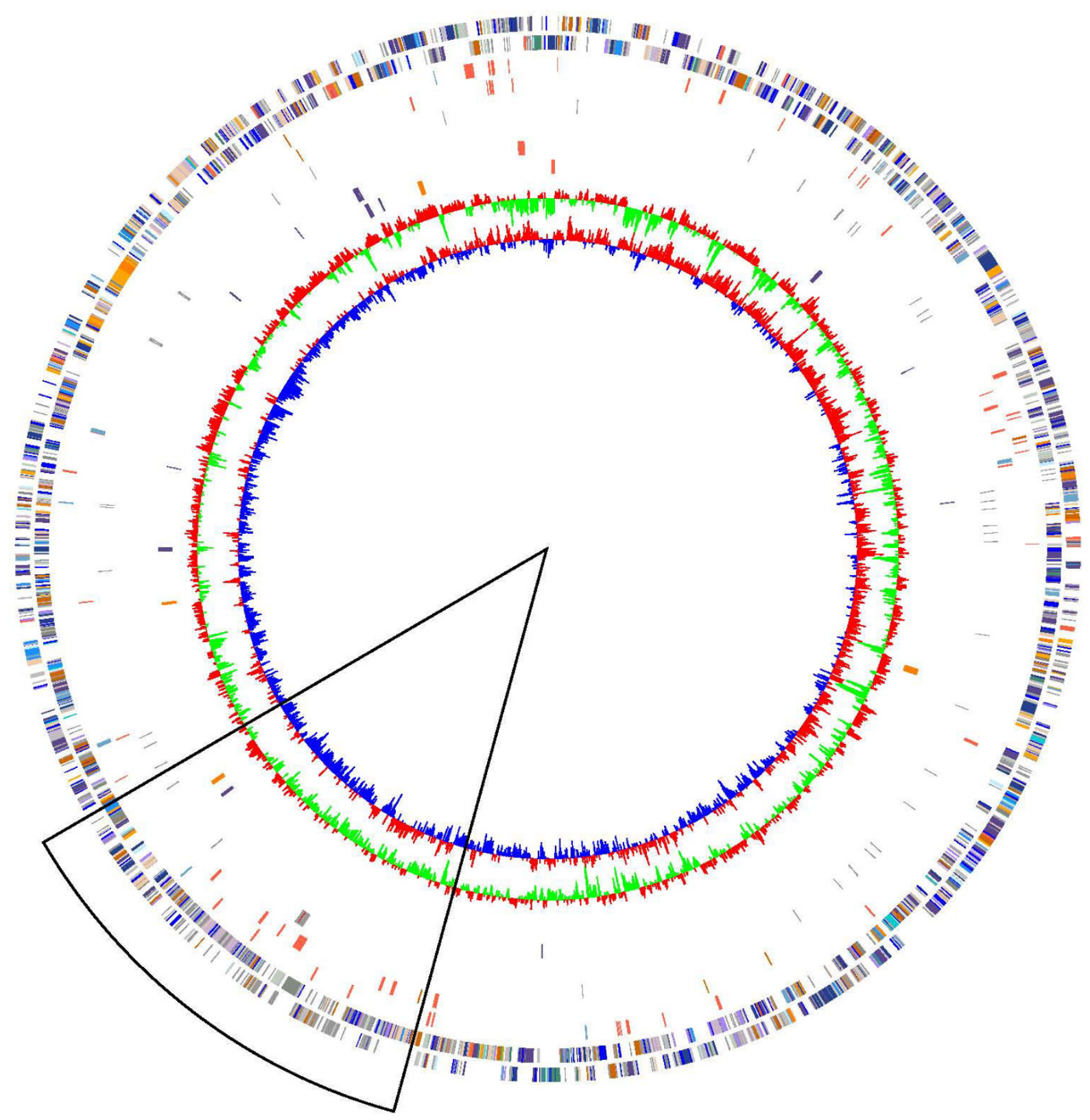

Figure 2

Circular representation of the $A$. ferrooxidans ATCC 23270 genome sequence. The two outer circles represent predicted protein encoding-genes on the forward and reverse strands, respectively. Functional categories are indicated by color, as follows: energy metabolism (green), DNA metabolism (red), protein synthesis (magenta), transcription (yellow), amino acid metabolism (orange), central intermediary metabolism (dark blue), cellular processes (light blue), nucleotide metabolism (turquoise), hypothetical and conserved hypothetical proteins (grey), mobile and extra-chromosomal elements (black), and general functions (brown). The third and fourth circles (forward and reverse strands) indicate major transposases and mobile elements (orange), plasmid-related genes (red), and phage elements (blue). The fifth and sixth circles (forward and reverse strands) indicate tRNA genes (gray). The seventh and eighth circles (forward and reverse strands) show genes predicted to be involved in sulfur (purple), iron (red), and hydrogen (orange) oxidation. The ninth and tenth circles show genomic GC bias and GC skew, respectively. 
Table I: General features of the A. ferrooxidans ATCC 23270 genome.

\begin{tabular}{|c|c|}
\hline Characteristic & Value \\
\hline Complete genome size, bp & $2,982,397$ \\
\hline $\mathrm{G}+\mathrm{C}$ percent $(\%)$ & 58.77 \\
\hline Total number of CDSs & 3,217 \\
\hline Coding density (\%) & 97.45 \\
\hline No. of rRNA operons (I6S-23S-5S) & 2 \\
\hline No. of tRNA genes & 78 \\
\hline Proteins with known function & 2,070 \\
\hline Conserved hypothetical proteins & 388 \\
\hline Hypothetical proteins & 759 \\
\hline Most represented functional categories & (\%) \\
\hline Cell envelope & 7.8 \\
\hline Transport and binding proteins & 7.61 \\
\hline Energy metabolism & 6.52 \\
\hline Best BLASTP comparisons against complete proteomes & Number of best blast hits \\
\hline$\gamma$-proteobacteria & 899 \\
\hline$\beta$-proteobacteria & 791 \\
\hline$\alpha$-proteobacteria & 271 \\
\hline$\delta$-proteobacteria & 103 \\
\hline Cyanobacteria & 73 \\
\hline Archaea & 41 \\
\hline
\end{tabular}

of $\mathrm{CO}_{2}$ fixation in $A$. ferrooxidans (no strain designated) [30]. Several enzymes of the Calvin cycle have been described in A. ferrooxidans, including the key D-ribulose1,5-bisphosphate carboxylase/oxygenase (RuBisCO) [29]. Two structurally distinct forms of RuBisCO (I and II), with different catalytic properties, are typically present in autotrophs [31]. Genes encoding Form I (AFE3051-2) have been cloned and characterized from A. ferrooxidans $[32,33]$. Gene clusters potentially encoding a second copy of Form I (AFE1690-1) and a copy of Form II (AFE2155) were predicted and shown to be differentially expressed depending on whether A. ferrooxidans was grown on ironor sulfur-containing medium. [34]. A gene predicted to encode a novel Rubisco-like protein known as Form IV [35] was recently identified in the genome (AFE0435) and is suggested to be involved in stress response (EsparzaMantilla, personal communication) (Additional file 2).

The genomic organization of the three gene clusters encoding the Rubisco type I and II enzymes in A. ferrooxidans is similar to that found in Hydrogenovibrio marinus strain MH-110, an obligate chemolithoautotrophic, hydrogen-oxidizing, marine bacterium. In $H$. marinus, these three-gene clusters are regulated in response to $\mathrm{CO}_{2}$ concentration, suggesting the ability to adapt to environmental conditions with different levels of $\mathrm{CO}_{2}[36]$.

\subsection{Energy metabolism}

\subsection{Aerobic Iron oxidation}

Since ferrous iron [Fe(II)] is rapidly oxidized by atmospheric oxygen at neutral $\mathrm{pH}$, iron exists primarily in the oxidized form [Fe(III)] in aerobic environments. Therefore, ferrous iron is available for microbial oxidation principally in acidic environments where chemical oxidation is slow and Fe(II) is soluble, in anoxic conditions such as in marine sediments and at the interface between aerobic and anaerobic atmospheres [37]. In anoxic conditions, phototrophic bacteria can use light energy to couple the oxidation of $\mathrm{Fe}(\mathrm{II})$ to reductive $\mathrm{CO}_{2}$ fixation. Although little is known about the mechanisms involved, this process has been postulated to be an ancient form of metabolism and to represent a transition step in the evolution of oxygenic photosynthesis [38,39].

The bioinformatics analysis of the genome sequence of $A$. ferrooxidans has permitted the identification of the main components of the electron transport chain involved in iron and sulfur oxidation (Figure 3). Genes encoding iron oxidation functions are organized in two transcriptional units, the petI and rus operons. The petI operon (petC-1, petB-1, petA-1, sdrA-1, and $c y c A-1$; AFE3107-11) encode the three subunits of the $b c_{1}$ complex (PetCAB), a predicted short chain dehydrogenase ( $\mathrm{Sdr}$ ) of unknown function, and a cytochrome $c_{4}$ that has been suggested to 
A
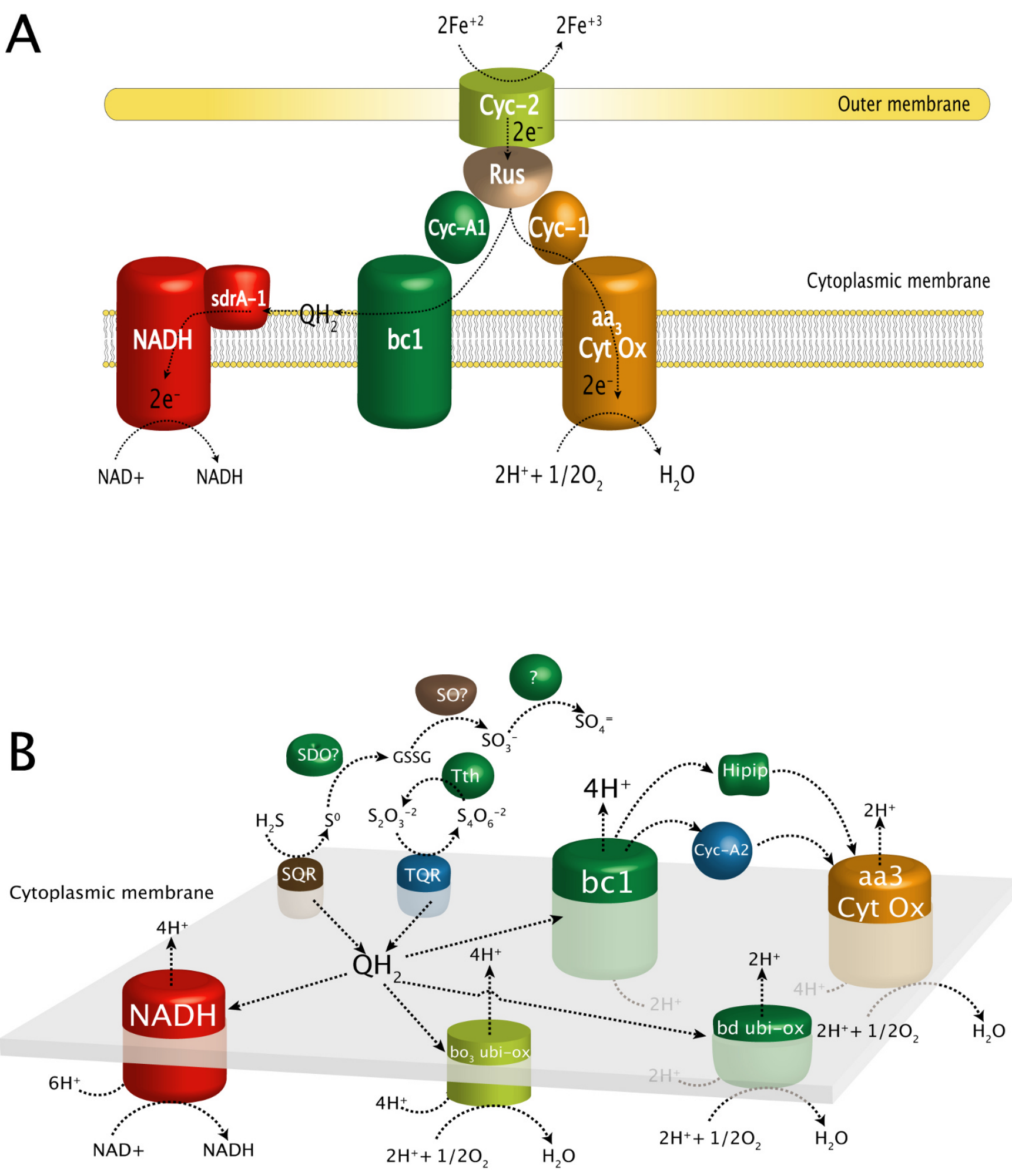

\section{Figure 3}

Genome-based models for the oxidation of ferrous iron and reduced inorganic sulfur compounds (RISCs). Schematic representation of enzymes and electron transfer proteins involved in the oxidation of $(A)$ ferrous iron and (B) reduced inorganic sulfur compounds (RISCs). Proteins and protein complexes are described in the text. 
receive electrons from rusticyanin and pass them to the $b c_{1}$ complex [5]. The petI operon has been analyzed experimentally in A. ferrooxidans strain ATCC 19859 [5] and recently in strain ATCC33020 [8].

The rus operon $(c y c 2, c y c 1, h y p, \operatorname{cox} B, \operatorname{cox} A \operatorname{cox} C$, $\operatorname{cox} D$, and rus; AFE3146-53) encodes two c-type cytochromes (Cyc1 and Cyc2), components of the aa3-type cytochrome oxidase (CoxBACD), and rusticyanin, respectively [40]. Cyc2 has been shown to accept electrons directly from Fe(II) and, given its location in the outer membrane, may carry out the first step in $\mathrm{Fe}(\mathrm{II})$ oxidation [41]. These proteins are thought to form a "respiratory supercomplex" that spans the outer and the inner membranes and transfers electrons from iron (or pyrite) to oxygen $[40,42,43]$. Based on transcriptional, biochemical, and genetic studies [28], it was proposed that electrons from ferrous iron oxidation flow through $\mathrm{Cyc} 2$ to rusticyanin. From there, some of the electrons feed the "downhill electron pathway" through $c$-cytochrome Cyc1 to $a a_{3}$ cytochrome oxidase, some the "uphill electron pathway" that regenerates the universal electron donor NADH by the reverse electron flow through $c$-cytochrome CycA1--> $b c_{1}$ complex->ubiquinone pool-->NADH dehydrogenase (Figure 3a).

Genome analysis suggests a solution to a long-standing controversy. A HiPIP (high potential iron-sulfur protein) encoded by iro has been postulated to be the first electron acceptor from $\mathrm{Fe}(\mathrm{II})[44,45]$. However, transcriptional studies of iro in A. ferrooxidans ATCC33020 suggested that it may be involved in sulfur oxidation. In our analysis of the type strain, iro (AFE2732) was found to be associated with the petII gene cluster thought to be involved in sulfur oxidation $[46,47]$, thus making it unlikely that Iro is the key iron-oxidizing enzyme.

\subsubsection{Aerobic oxidation of reduced inorganic sulfur compounds (RISCs)}

Genes encoding enzymes and electron transfer proteins predicted to be involved in the oxidation of reduced inorganic sulfur compounds (RISCs) were detected in the genome (Figure $3 \mathrm{~b}$ ). The oxidative and electron transfer pathways for RISCs are more complicated than those for $\mathrm{Fe}(\mathrm{II})$ oxidation, making their prediction and elucidation more difficult [48]. To add further complication, some steps occur spontaneously, without enzymatic catalysis. Previous experimental studies in various strains of $A$. ferrooxidans detected several enzymatic activities involved in the oxidation of RISCs $[1,28]$, but some of these activities had not been linked to specific genes. Based on genome analysis, some of these missing assignments are predicted and also some novel genes involved in the oxidation of thiosulfate, sulfide, and tetrathionate are suggested.
Experimentally validated components of RISC metabolism include: the pet-II operon (AFE2727-31) and alternative quinol oxidases of the $b d$ (AFE0954-5) and $b o_{3}$ families (AFE0631-4) [7,8]; a sulfide/quinone oxidoreductase encoded by sqr (AFE0267) suggested to be involved in the oxidation of sulfide to sulfur $[49,50]$; and a tetrathionate hydrolase encoded by tetH (AFE0029) thought to be involved in the oxidation of tetrathionate [51].

The two homologs of doxDA (AFE0044; AFE0048) present in the genome are predicted to encode a thiosulfate/quinone oxidoreductase. Both appear to be a fusion of the separate $\operatorname{doxD}$ and $\operatorname{dox} A$ genes that are found in other organisms such as A. ambivalens $[52,53]$. Both are located in a major gene cluster composed of two divergent gene clusters. The first region (AFE0050-47) encodes a protein with TAT-signal peptide (IPR006311, TIGR01409), a periplasmic solute-binding protein, the first doxDA gene, and a conserved hypothetical protein. The second region (AFE0046-42) encodes a conserved hypothetical protein, a rhodanese enzyme that splits thiosulfate into sulfur and sulfite [54], the second copy of $\operatorname{doxDA}$, a periplasmic solute-binding protein, a second copy of a gene encoding a protein with TAT-signal peptide (IPR006311, TIGR01409), and a gene encoding a putative carboxylate transporter. We have detected a similar organization in the Gluconobacter oxydans genome.

Five genes, predicted to encode thiosulfate sulfur transferase (rhodanese) proteins (AFE2558, AFE2364, AFE1502, AFE0529 and AFE0151) are dispersed in the genome [55] but their roles in sulfur oxidation remain to be firmly established. Notably, some of these predictions are based on the presence of the rhodanese PFAM00581 motif associated with phosphatases and ubiquitin C-terminal hydrolases, in addition to sulfur oxidation. Genes were not detected for several enzymatic functions that have been experimentally demonstrated in other strains of $A$. ferrooxidans including the sulfur dioxygenase that oxidizes persulfide-sulfur to sulfite in A. ferrooxidans strain R1 $[1,56]$ and the sulfite oxidase that oxidizes sulfite to sulfate in Ferrobacillus ferrooxidans [1,57].

\subsubsection{Hydrogen and formate utilization}

Hydrogen utilization has been demonstrated experimentally in A. ferrooxidans ATCC 23270 [9] and a group 2 hydrogenase from A. ferrooxidans ATCC 19859 has been characterized [58], but there were no previous reports describing the hydrogenase genes and their genetic organization or their potential diversity. The A. ferrooxidans genome encodes four different types of hydrogenases based on the 2001 classification by Vignais et al. [59] (Figure 4, Additional file 3). Group 1 [NiFe]-hydrogenases are membrane-bound respiratory enzymes that enable the 
A Respiratory hydrogenase (group 1)

Uptake hydrogenase (group 2)
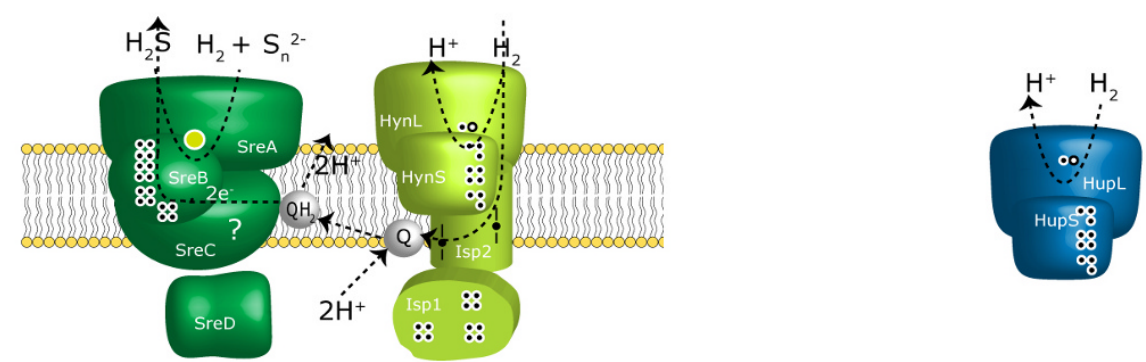

Reversible hydrogenase (group 3)

H2-evolving hydrogenase (group 4)
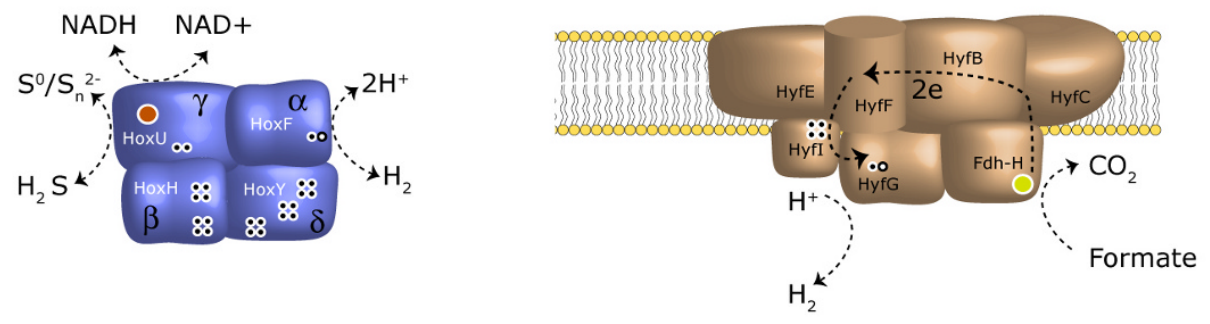

B

Respiratory hydrogenase (group 1)

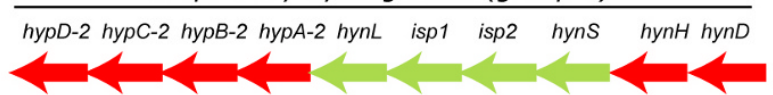

Other function hypothetical proteins

Transcription factors hydrogenase biosynthesis

Group-1 H2ase Group-2 H2ase

Group-3b H2ase Group-4 H2ase

Uptake hydrogenase (group 2)

hypB-1 hypA-1 hypE hypD-1 gmhA hypC-1 hypF NHL-prot Iscbp mhyp AF0708 AF0707 HupW AF0704 AF0703 hupL hupS hupR cysB-2

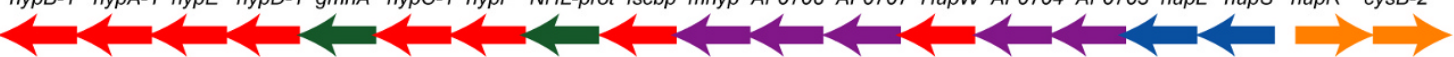

$\frac{\text { Reversible hydrogenase (group 3) }}{\text { hoxH hoxy hoxU hoxf hoxW AF0935 }}$

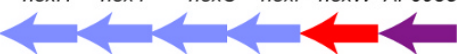

$\frac{\text { H2-evolving hydrogenase (group 4) }}{\text { hyfl hyfG hyfF hyfE hyfC hyfB }}$

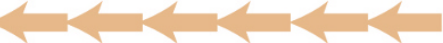

C
A. ferrooxidans

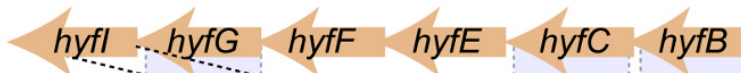
M. barkeri
A. ferrooxidans

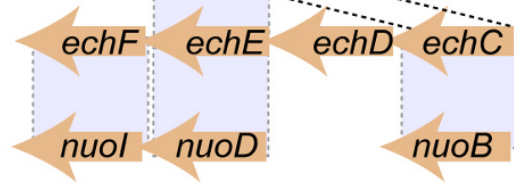
echB echA
nuoB
nuOL

\section{Figure 4}

Diversity and genomic organization of predicted hydrogenases. A) Schematic representation of the four predicted types of hydrogenase. B) Organization of the predicted operons encoding the four types of hydrogenase. C) Schematic representation of similarity between the group 4 hydrogenase genes in $M$. barkeri with the $A$. ferrooxidans group 4 hydrogenase (above) and NADH dehydrogenase subunits (below). 
cell to use molecular hydrogen as an energy source. A. ferrooxidans has both the predicted structural (AFE3283-86) and the maturation-related genes (AFE3281-2; AFE328790) required for production of a functional respiratory hydrogenase of this type. In addition, the small subunit of this predicted complex has the characteristic TAT-signal peptide used to target the full heterodimer to the periplasmic space [60]. The genomic arrangement of the structural genes (hynS-isp1-isp2-hynL) is identical to that found in a thermoacidophilic archaeon (Acidianus ambivalens), a hyperthermophilic bacterium (Aquifex aeolicus), a denitrifying bacterium (Thiobacillus denitrificans), and two phototrophic sulfur bacteria (Thiocapsa roseopersicina and Allochromatium vinosum). Like A. ferrooxidans, all of these bacteria are chemoautotrophs that live in extreme environments, use inorganic energy sources, and have an active sulfur metabolism that oxidizes and reduces inorganic sulfur compounds [61].

A. ferrooxidans also encodes a group 2 cytoplasmic uptake [NiFe]-hydrogenase (AFE0701-2). Group 2 hydrogenases are induced during nitrogen fixation to utilize the molecular hydrogen generated [62]. The cyanobacterial-like hydrogenase in $A$. ferrooxidans exhibits the characteristic features of uptake hydrogenases as determined by EPR and FTIR [63]. Divergently oriented from the group 2 hydrogenase gene cluster is a predicted $\sigma_{54}$-dependent hydrogenase transcriptional regulator ( $h u p R$ ) (AFE0700). HupR together with a histidine kinase forms part of a twocomponent regulatory system in R. eutropha [64], but the histidine kinase appears to be absent from the A. ferrooxidans genome. Despite that, HupR is able to activate transcription in the non-phosphorylated form [65-67], indicating that HupR is still able to regulate transcription of the group 2 hydrogenase system in A. ferrooxidans.

Adjacent to the group 2 hydrogenase gene cluster and transcribed in the same direction is a predicted cysteine regulon transcriptional activator $c y s B$ (AFE0699). This is followed by a cluster of genes potentially involved in fermentation, including a predicted $\sigma_{54}$-dependent transcriptional regulator and a group of isc-like genes (AFE0672-78). The latter gene group is thought to be involved in assembling the iron-sulfur cluster of the nitrogenase used in nitrogen fixation, thus suggesting a connection between hydrogen production by the group 2 hydrogenase and nitrogen fixation [68]. The close proximity of the fermentation gene cluster suggests an additional metabolic coupling with fermentative metabolism, perhaps as part of a $\sigma_{54}$ regulatory cascade operating in anaerobic or microaerophilic conditions.

The third predicted hydrogenase encodes a sulfhydrogenase, a group $3 \mathrm{~b}$ cytoplasmic, bidirectional, heterotetrameric hydrogenase. This hydrogenase, in association with other proteins, binds soluble cofactors such as NAD, cofactor 420, and NADP [59]. Domain analysis predicts an F420 binding site in the $\alpha$ subunit (large hydrogenase subunit; AFE0937) and NAD- and FAD-binding sites in the $\gamma$ subunit (AFE0939). The predicted NAD-binding site suggests that $A$. ferrooxidans can use NADPH as an electron donor, as has been shown for Pyrococcus furiosus [69]. A possible role for this hydrogenase could be the recycling of redox cofactors using protons or water as redox counterparts, as has been suggested for Alcaligenes eutrophus, thus serving as an electron sink under high reducing conditions [66].

The gene organization and amino acid sequence of a sixgene cluster (AFE2149-54) (Figure 4c) shows significant similarity to the group $4 \mathrm{H}_{2}$-evolving hydrogenase complex found in several organisms (e.g., Methanococcus barkeri [70]). In $M$. barkeri, this cluster encodes a six-subunit complex that catalyzes the energetically unfavorable reduction of ferrodoxin by $\mathrm{H}_{2}$, possibly driven by reverse electron transport. The reduced ferrodoxin produced then serves as a low-potential electron donor for the synthesis of pyruvate in an anabolic pathway [71]. Reverse electron flow for the production of NADH via the oxidation of $\mathrm{Fe}(\mathrm{II})$ in $A$. ferrooxidans has been shown to be driven by the proton motif force (PMF) across its membrane that results from the acidity of its environment [72]. The predicted activity of the group 4 hydrogenase complex may exemplify another where A. ferrooxidans exploits the natural PMF to generate reducing power and couple it to redox reactions.

Another possible role for the group 4 hydrogenase complex involves the oxidation of formate. Two clusters of three genes (AFE1652-4 and AFE0690-2) potentially encode a formate dehydrogenase complex consisting of a formate dehydrogenase accessory protein FdhD-1, a hypothetical protein, and a molybdopterin formate dehydrogenase. The second cluster is divergently oriented from a gene encoding a predicted $\sigma_{54}$-dependent transcriptional regulator. It has been reported that this complex associates with a hydrogenase group 4 complex in $E$. coli to create a formate hydrogenase supercomplex [73]. We propose a similar model for $A$. ferrooxidans, thus offering a biochemical basis for its ability to oxidize formate [10].

\subsubsection{Anaerobic metabolism}

Several strains of $A$. ferrooxidans have been reported to use electron acceptors other than $\mathrm{O}_{2}$, including the use of ferric iron for the oxidation of sulfur and hydrogen and the use of sulfur for the oxidation of hydrogen by A. ferrooxidans JCM 7811 [74]. In that strain, the reduction of ferric iron was accompanied by the increased expression of a 28 $\mathrm{kDa}$-type cytochrome that was suggested to be responsible for this activity [74]. The reduction of ferric iron dur- 
ing sulfur oxidation was also shown for the type strain ATCC 23270 [75]. However, a gene potentially encoding this cytochrome could not be identified in A. ferrooxidans ATCC 23270 [76]. A candidate iron reduction complex has been investigated in A. ferrooxidans AP19-3 by electrophoretic purification and enzymatic assays $[77,78]$. However, potential genes encoding this complex could not be detected in our genome analysis.

The use of sulfur as an electron acceptor was investigated in A. ferrooxidans NASF-1 where aerobically grown cells were found to produce hydrogen sulfide from elemental sulfur using NADH as electron donor via a proposed sulfur reductase [79]. However, the observed molecular weights of the subunits of this sulfur reductase do not correspond to those predicted from an analysis of the group $3 \mathrm{~b}$ hydrogenase genes in the type strain genome, with the caveat that post-translational modifications could explain the differences in molecular weights. However, a gene cluster (AFE2177-81) was detected in the type strain that is predicted to encode a sulfur reductase enzyme with significant similarity of amino acid sequence and gene order to the cluster suggested to be responsible for sulfur reduction in Acidianus ambivalens [80]. We hypothesize that this enzyme could associate with the predicted group 1 hydrogenase to form a supercomplex, facilitating the use of hydrogen as an electron and energy source with sulfur serving as the final electron acceptor.

\subsection{Nitrogen metabolism}

A. ferrooxidans can meet its nitrogen needs by either nitrogen fixation or ammonia assimilation. Diazotrophic growth of A. ferrooxidans was first demonstrated in early studies of acetylene reduction and ${ }^{15} \mathrm{~N}_{2}$ assimilation [15] and the structural genes for the nitrogenase complex were later sequenced [81-83].

\subsection{Ammonia uptake and utilization}

The A. ferrooxidans genome contains genes predicted to be involved in ammonia uptake (amt1, amt2 and amtB; AFE2916, AFE2911, and AFE1922). Amt1 and amt2 are located in a gene cluster that includes a gene potentially encoding a class-I glutamine amidotransferase (AFE2917) that has been shown in other organisms to transfer ammonia derived from the hydrolysis of glutamine to other substrates. GlnK-1 (AFE2915) is also present in this cluster and is predicted to encode a P-II regulatory protein involved in the regulation of nitrogen metabolism in response to carbon and glutamine availability [84]. A glnA homolog (AFE0466) is predicted to encode a type I glutamine synthase that would permit the incorporation of ammonia directly into glutamine, completing the inventory of genes necessary for ammonia uptake and utilization.

\subsubsection{Nitrogen Fixation}

A putative nitrogenase gene cluster (nifH-D-K-fer1-fer2-E$N$-X; AFE1522-AFE1515) (Additional file 4) was previously reported in the type strain [68]. These genes potentially encode the nitrogenase complex and proteins involved in the synthesis of the nitrogenase MoCo cofactor. In other organisms, nitrogenase has been shown to be oxygen sensitive and its expression and activity are regulated at both the transcriptional and post-translational levels [84]. Divergently oriented from the nif operon is a cluster of genes involved in the regulation of nitrogenase activity. The first gene of this cluster is a putative $\sigma_{54}$ response regulator (AFE1523). This is followed by the draT and draG genes (AFE1524, AFE1525) that encode a dinitrogen-reductase ADP-D-ribosyltransferase and a ADP-ribosyl-[dinitrogen reductase] hydrolase, respectively. These two are involved in the post-translational modulation of nitrogenase activity in response to ammonium and oxygen concentrations [84]. NifA (AFE1527) is also present in the same gene cluster. NifA potentially encodes an enhancer binding protein that, together with $\sigma_{54}$, is involved in the transcriptional activation of the nif operon in response to the redox, carbon, and nitrogen status. This ensures that nitrogen fixation occurs only under physiological conditions that are appropriate for nitrogenase activity [85].

Using this genomic information, a gene network for the regulation of nitrogen fixation and ammonia uptake can be suggested for $A$. ferrooxidans that is consistent with similar models derived from other organisms (Figure 5) [84]. In this model, NifA (AFE1527) is the transcriptional activator of the nitrogenase operon and its expression is regulated by a two-component regulatory system encoded by $n t r B$ and $n t r C$ (AFE2902, AFE2901) that measure oxygen and nitrogen levels. These signals are integrated by the PII proteins $(g \ln K-1, \mathrm{AFE} 2915 ; g \ln B-1, \mathrm{AFE} 2462 ; g \ln K-2$, AFE2240; and $g \ln B-2$, AFE0429) with additional metabolic signals, such as fixed carbon and energetic status [86]. Two additional copies of $n \operatorname{tr} C$ and $n t r B$, termed $n \operatorname{tr} Y$ and $n \operatorname{tr} X$ (AFE0024, AFE0023) have been detected in the genome that could allow cross talk between the sensor/ regulator pairs NtrY/X and NtrB/C, as described in Azospirillum brasilense [87]. The redundancy of the regulatory genes responsible for nitrogen fixation and assimilation suggests the presence of a flexible mechanism that is responsive to environmental changes.

\section{Nutrient uptake and assimilation systems}

A. ferrooxidans has 72 genes $(2.23 \%)$ predicted to be involved in nutrient uptake (Additional file 3) whereas most heterotrophic $\gamma$-proteobacteria typically dedicate about $14 \%$ of their genome information to transport functions [88]. The potential substrates incorporated include phosphate, sulfate, iron, ammonia, organic acids, 


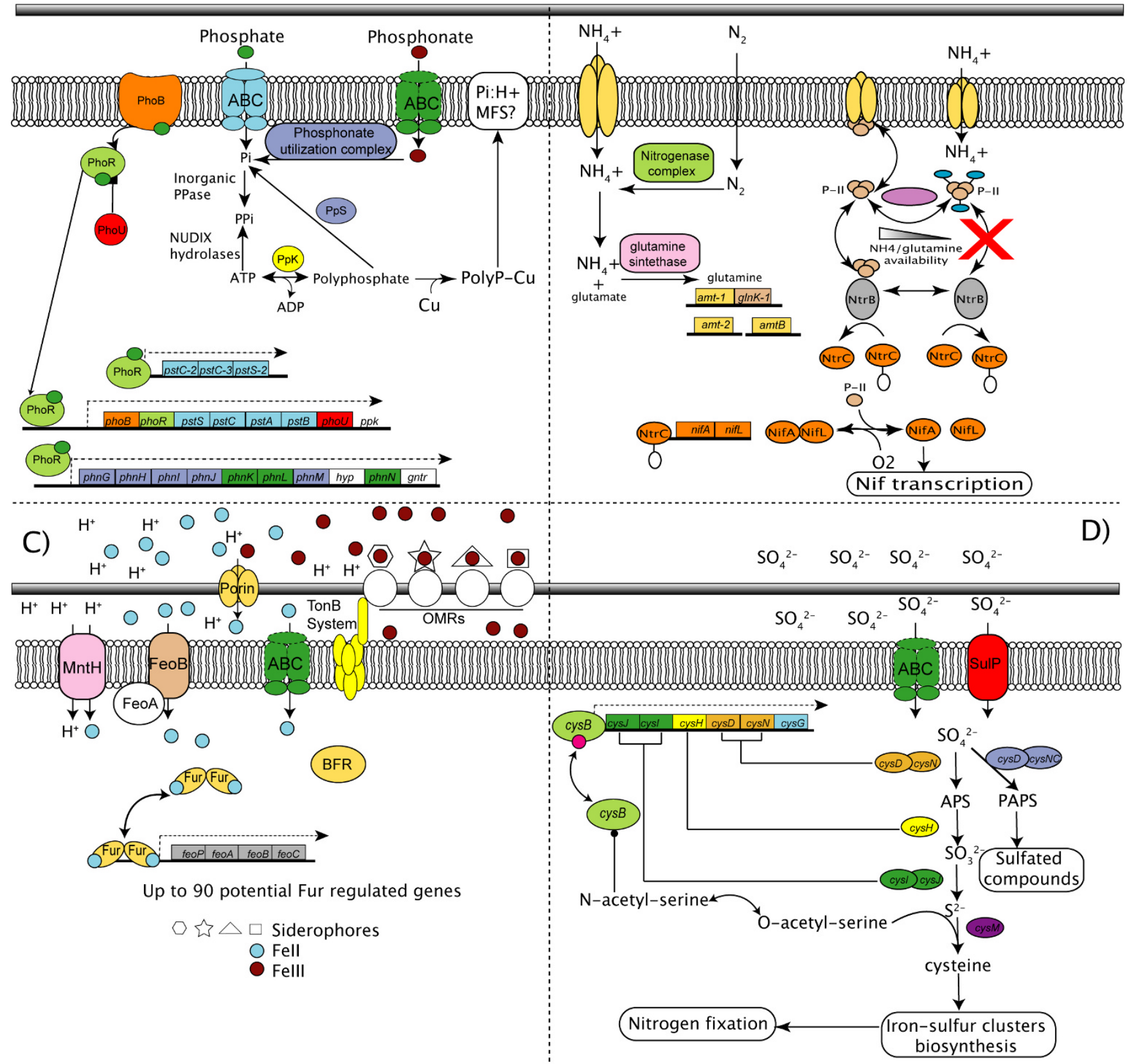

Figure 5

Predicted regulatory models for inorganic ion uptake and assimilation. A) Phosphate and phosphonate. B) Nitrogen and ammonia. C) Ferric and ferrous iron. D) Sulfate. Proteins and protein complexes are described in the text.

amino acids, and sugars. This repertoire, especially the low representation of predicted carbohydrate uptake systems, is a signature of obligate autotrophic bacteria [88].

\section{I Inorganic ion assimilation}

\section{I.I Sulfate}

A gene for a predicted sulfate permease (AFE0286) of the SulP family is present in the genome adjacent to a poten- tial carbonic anhydrase gene (AFE0287). This linkage has been observed in many bacteria [89], suggesting that the gene pair forms a sulfate/carbonate antiporter system. Sulfate taken up from the environment is thought to be reduced to sulfide for cysteine biosynthesis by a group of genes belonging to the cys regulon [68]. 


\section{I.2 Phosphate}

Previous investigations of phosphate metabolism in $A$. ferrooxidans provided evidence for a phosphate starvation response [90] and for a relationship between polyphosphate degradation and heavy metal resistance and efflux [91]. However, we still lacked a comprehensive understanding of all the potential components involved in phosphate metabolism, as well as their integration and regulation. Our genome analysis identified a complete repertoire of the genes necessary for phosphate uptake by the high affinity Pst-transport system. These predicted genes are arranged in two similar clusters. The first cluster (AFE1939-41) includes two genes ( $p s t C-1$ and $p s t C-2)$ that encode a phosphate permease and a third gene ( $p s t S-1)$ that encodes a periplasmic phosphate binding protein. The second gene cluster (AFE1441-1434) includes a gene encoding a exopolyphosphatase ( $p p x$, AFE1441) previously described to be involved in heavy metal resistance and efflux [91], phoU (AFE1440) predicted to encode a phosphate transport regulatory protein, pstB encoding an ATP binding protein, and $p s t A$ coding for the permease component. In addition, there are genes encoding a third homolog of the phosphate permease PstC-3, a second homolog of the periplasmic phosphate binding protein PstS-2, and the two-component response regulator PhoR/ PhoB.

The predicted phosphonate utilization gene cluster (AFE2278-86) contains genes for C-P cleavage and an ATP-binding protein for the $\mathrm{ABC}$ phosphonate transport system. In spite of the experimental evidence reported about the utilization of phosphonate in this bacterium [92], the typical permease subunit that is required to complete phosphonate uptake was not found in the genome.

The genome does contain a gene (AFE1876) for a predicted polyphosphate kinase (Ppk) involved in polyphosphate storage. It has been suggested to be part of a pho regulon whose expression is activated during phosphate starvation [89] and in response to heavy metal toxicity [91].

\section{I.3 Iron}

Genomic evidence indicates that $A$. ferrooxidans relies on diverse standard iron uptake mechanisms to obtain both $\mathrm{Fe}$ (II) and $\mathrm{Fe}$ (III) (93). The type strain has candidate genes (AFE2523-AFE2525) potentially encoding the FeoABC $\mathrm{Fe}(\mathrm{II})$ inner-membrane transport system and an NRAMP dual Mn(II)/Fe(II) MntH-like transporter (AFE0105). Previously reported gene context analysis indicated that $f e o A$, $f e o B$, and $f e o C$ form part of an iron-regulated operon, along with an ORF (AFE2522) encoding a putative porin (designated $f e o P$ ) that could facilitate entrance of $\mathrm{Fe}(\mathrm{II})$ into the periplasm [93].
A. ferrooxidans is typically confronted with an exceptionally high concentration of soluble iron in its acidic environment, as high as $10^{-1} \mathrm{M}$ compared to $10^{-16} \mathrm{M}$ in typical neutrophilic environments. This raises questions as to the mechanisms it uses for iron assimilation and homeostatic control of internal iron concentrations. Given the abundance of both $\mathrm{Fe}$ (II) and $\mathrm{Fe}$ (III) in its environment, A. ferrooxidans has a surprisingly large number of iron uptake systems, including eleven distinct putative genes encoding TonB-dependent outer membrane receptors $(t d r)$ for high affinity uptake of siderophore-chelated $\mathrm{Fe}(\mathrm{III})$ ( $t d r A$, AFE2935; $t d r C$, AFE1483; $t d r D$, AFE1492; $t d r E$, AFE2040; $t d r F$, AFE2998; $t d r G$, AFE2302; $t d r H$, AFE2298; $t d r I$, AFE2292; $t d r J$, AFE2288; $t d r K$, AFE0763; $t d r L$, AFE3229). Also, it has a number of copies of all the accessory genes needed to transport iron into the cytoplasm, including seven different copies of the energy transduction genes tonB (AFE3002, AFE2304, AFE2301, AFE2275, AFE2268, AFE1487, AFE0770) and exbB (AFE3003, AFE2299, AFE2273, AFE2270, AFE1485, AFE0768, AFE0485) and six copies of exbD (AFE3004, AFE2300, AFE2269, AFE1486, AFE0769, AFE0486), as well as the genes encoding two different ABC iron transporters (AFE1489AFE1491, AFE1493-AFE1495). No genes were detected that might be involved in standard mechanisms of siderophore production. However, its multiple siderophore uptake systems suggest that it is nonetheless capable of living in environments where iron is scarce (perhaps at higher $\mathrm{pH}$ values) and in which other organisms capable of producing siderophores are present.

For Fe(III) uptake, all the genes involved are organized in seven gene clusters, some of which include additional gene functions [22]. One cluster encodes a complete suite of proteins necessary for $\mathrm{Fe}$ (III) uptake (AFE1482AFE1495) that includes not only two outer membrane receptors (OMRs) of different predicted siderophore specificities, but also three different ABC solute-binding proteins with affinity for iron and molybdenum and may be a dedicated iron-molybdenum transport system that is present in a genomic island [94]. This predicted operon also includes a putative gene ( $g l o A$, AFE1482) predicted to encode a globin-like protein that has been suggested to be an oxygen sensor regulating the expression of $\mathrm{Fe}-\mathrm{Mo}$ uptake [94]. GloA is also associated with an upstream Fur box, indicating possible regulation via the master iron regulator Fur [21].

\subsection{Carbon compound uptake \\ 3.2.I Amino acids}

Among the predicted nutrient transport genes in the A. ferrooxidans genome are five amino acid permeases of unknown specificity (AFE2659, AFE2457, AFE1782, AFE0719, and AFE0439) (the same number as found in the chemolithoautotroph T. crunogena) and one complete 
ABC system for dipeptide uptake (AFE2987-92). The addition of leucine to solid media has been reported to improve the yield of A. ferrooxidans ATCC 33020 during the first ten days of growth, whereas the addition of cysteine or methionine inhibits growth [95]. More recently, the addition of minimal concentrations of glutamate to liquid media was found to accelerate the growth rate of A. ferrooxidans ATCC 23270 (Omar Orellana, personal communication).

\subsubsection{Carbohydrate uptake}

The suite of genes for carbohydrate transport appears to be limited, as has been found in most obligate autotrophs (e.g., T. denitrificans [96], T. crunogena [88], M. capsulatus [97], N. europea [98], and N. oceanii [99]). This suite of predicted genes includes two outer membrane carbohydrate selective porins of the OPRB family (AFE2522, AFE2250), one carbohydrate transporter of unknown specificity (AFE2312) that is related to the major facilitator superfamily (PF00083, PS50850) and very similar to xylose and galactose proton symporters $[100]$, and an MFS transporter (AFE1971) with marginal similarity to sugar/nucleoside symporters. It also includes genes for an incomplete PTS system for carbohydrate uptake (AFE3018-23) potentially encoding EII-A, a kinase/phosphatase HprK, an ATPase, an IIA component, a phosphocarrier protein $\mathrm{Hpr}$, and a phosphoenolpyruvate phosphotransferase. However, we could not identify a gene encoding the IIC sugar permease component, thus making it unlikely that $A$. ferrooxidans has a functional sugar-transporting PTS system. Instead, we suggest that this PTS system could be involved in molecular signaling as part of a regulatory cascade involving $\mathrm{RpoN}$, as described in other proteobacteria [101]. In this model, a decrease of fixed carbon leads to low levels of phosphoenolpyruvate and cyclic-AMP that in turn maintain most PTS proteins in the dephosphorylated form. This promotes the utilization of glycogen as a carbon source to replenish the phosphoenolpyruvate levels, thus restoring the levels of phosphorylated PTS proteins [102].

\section{Central carbon metabolism}

It has been shown in many organisms that the 3-phosphoglyceraldehyde generated by $\mathrm{CO}_{2}$ fixation via the Calvin cycle enters the Embden-Meyerhof-Parnass pathway, thus providing fixed carbon that can be channeled in either of two directions: for glycogen biosynthesis and storage, or to provide carbon backbones for anabolic reactions. The genes predicted for these two pathways in A. ferrooxidans, together with their reactions and potential interconnections with other biosynthetic pathways, are shown in Figure 6.

\section{I Carbon storage and utilization}

The genome also contains genes predicted to encode the five enzymes required for glycogen biosynthesis from
fructose-6P. As has been shown in other organisms, glucose-1P-adenylyltransferase $(\mathrm{glg} C, \mathrm{AFE} 2838)$ is predicted to synthesize ADP-glucose. A specific glycogen synthase ( $g \lg A$, AFE2678) would then transfer the glucosyl moiety of ADP-glucose to a glycogen primer to form a new 1,4glucosidic bond. Subsequently, a branching enzyme $(g \lg B, A F E 2836)$ is predicted to catalyze the formation of branched 1,6-glucosidic linkages.

The carbon stored in glycogen is thought to be released by glucan phosphorylase ( $g l g P 1$, AFE1799; glgP2, AFE0527), thus regenerating glucose- $1 \mathrm{P}$ from the non-reducing terminus of the 1,4 chain. The pathway for the conversion of glucose-6P to 2-dehydro-3-deoxy-gluconate is also predicted to be present, except for the last step that replenishes the levels of pyruvate and 3P-glycerate. In addition, a gene encoding phosphoribulokinase was not detected, thus suggesting that either alternate genes encode the missing functions or else that $A$. ferrooxidans regenerates pyruvate and 3P-glycerate from stored glycogen by alternate pathways. Expression data obtained from A. ferrooxidans growing with sulfur and iron as energy sources have shown that genes involved in glycogen synthesis and utilization are differentially expressed [103]. Specifically, growth in sulfur-containing media preferentially activates genes involved in glycogen biosynthesis, whereas growth on iron-supplemented media upregulates genes involved in glycogen breakdown. This suggests that $A$. ferrooxidans channels fixed carbon to glycogen when sulfur is available as an energy source and uses glycogen as a reserve carbon donor when iron is the energy source.

\subsection{Carbon backbone formation}

The genome contains three genes (AFE1802, AFE1676 and AFE3248) that are predicted to encode fructose biphosphate aldolase (EC. 4.1.2.13), the enzyme that catalyzes the formation of fructose-1,6-bP. The interconversion of fructose-1,6-bP to fructose-6P in most heterotrophic bacteria is carried out by fructose biphosphatase and phosphofructokinase enzymes. In A. ferrooxidans, a gene encoding a fructose biphosphatase enzyme was found (AFE0189) that we suggest allows a direct flux of fixed carbon to glycogen storage. A potential phosphofructokinase candidate gene (AFE1807) was also found, a member of the PfkB family of sugar kinases (cd01164). It is located near putative genes involved in glycolysis/glyconeogenesis (e.g., phosphoglycerate mutase and phosphoenolpyruvate synthase), thus generating a bidirectional metabolic path for the utilization/generation of glycogen.

Putative genes for all the enzymes involved in the conversion of glyceraldehyde-3-P to pyruvate and acetyl-coA, as well as for the citric acid (TCA) cycle, were detected with the exception of genes encoding the E1-3 subunits of $\alpha$ ketoglutarate dehydrogenase. Thus, the TCA cycle is 


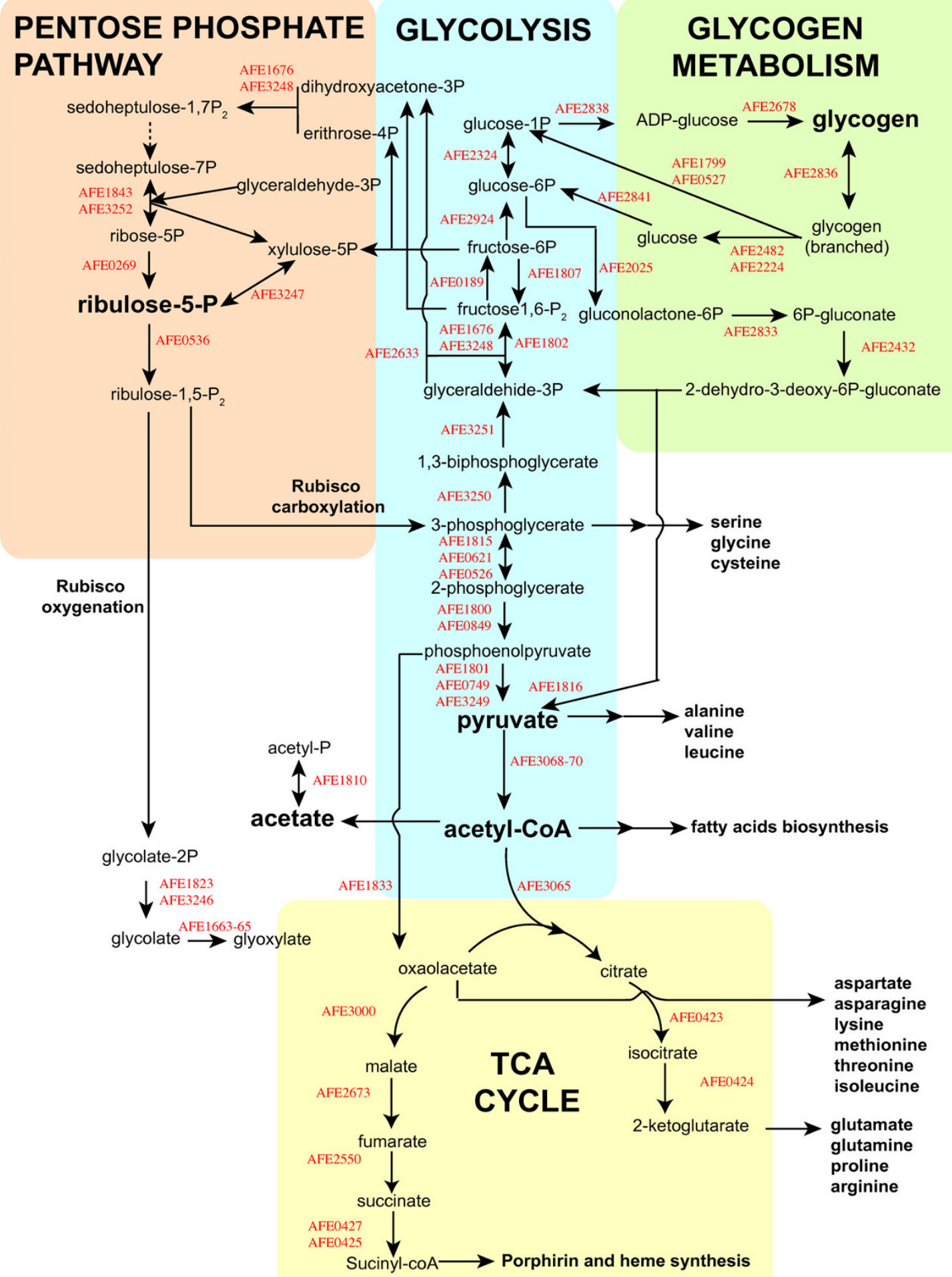

Figure 6

Predicted pathways (pentose phosphate pathway, glycolysis, glycogen and interrupted TCA cycle) for central carbon metabolism. 
incomplete, as has been described in a number of obligate autotrophic bacteria and archaea - a likely hallmark of this lifestyle [104].

\section{Heavy metal resistance}

Bioleaching microorganisms, such as A. ferrooxidans, typically live in environments that have high concentrations of soluble heavy metals (e.g., arsenic, mercury, and silver), as well as unusually high concentrations of potentially toxic metals (e.g., copper and iron). This has prompted numerous studies of the mechanisms employed by A. ferrooxidans for metal resistance [105]. In contrast to the genomic perspective presented herein, those investigations were conducted on multiple strains and thus do not provide a coherent view of the repertoire of heavy metal resistance genes present within one strain.

Our genome analysis confirmed the presence of a divergent gene cluster (AFE2857-60) previously identified as involved in arsenic resistance. The cluster includes genes encoding an arsenate reductase (ArsC), the arsenate repressor (ArsR), the divergently-oriented arsenate efflux pump (ArsB), and a hypothetical protein (ArsH). The arsCRB gene cluster was shown to confer resistance to arsenate, arsenite, and antimonium in E. coli, but the function of arsH is unknown [106,107].

Mercury resistance has been investigated in several strains of A. ferrooxidans [108-110]. Genome analysis of the type strain identified three genes potentially encoding the welldescribed Mer components, i.e., the repressor accessory protein (MerD, AFE2483), the mercury reductase (MerA, AFE2481), and the mercuric ion transporter (MerC, AFE2480). Four candidate genes potentially encoding members of the family of MerR-like transcriptional regulators were also found (AFE2607, AFE2509, AFE1431, and AFE0373).

The A. ferrooxidans genome also contains several genes (Additional file 3) predicted to be part of heavy metal tolerance systems [111], including genes for the copCD copper extrusion system, ten clusters of genes predicted to belong to the resistance-nodulation-cell division (RND) family of transporters, three genes encoding cation diffusion facilitator (CDF) proteins, three genes encoding copper translocating P-type ATPases, and two genes encoding other P-type ATPases of unknown specificity. These genome-based predictions offer new opportunities for experimental validation of heavy metal resistance in $A$. ferrooxidans and also provide new markers for detecting similar genes in other microorganisms

\section{Extrusion of toxic organic compounds}

The ability to extrude toxic organic compounds is widespread, and our inspection of the A. ferrooxidans genome suggests that this bacterium is well equipped to deal with toxic organic molecules. Its genome contains a gene predicted to encode the toluene tolerance protein $\operatorname{Ttg} \mathrm{D}$ (AFE1830) as well as a cluster of proteins often associated with toluene resistance that includes a Tol-Pal-associated acyl-CoA thioesterase (AFE0063) and TolBARQ (AFE0064-67).

The genome also includes a predicted complete $\mathrm{ABC}$ gene cluster (AFE0158-63) involved in drug extrusion that has significant similarity to the toluene $\mathrm{ABC}$ resistance proteins reported in other organisms. Resistance to toluene/ xylene and related aromatic hydrocarbons and organic solvents may be needed by A. ferrooxidans when growing in runoff from coal wastes where it might encounter aromatic hydrocarbons [112] or in bioleaching operation heaps that are irrigated with recycled water containing carboxylic acids and other organic compounds from solvent extraction operations [113].

An alternative hypothesis for the role of drug-related compound extrusion mechanisms present in microbes associated with biogeochemical cycles has been proposed [114]. A homolog of TolC has been shown in Shewanella oneidensis MR-1 to excrete anthraquinone-2,6-disulfonate (AQDS) that is used as an extracellular electron shuttle. It has been proposed that AQDS may be particularly important to transfer electrons from cells embedded in the interior of biofilms to reduce $\mathrm{Fe}(\mathrm{III})$ present in the solid substrate to which the biofilm is attached. It is possible that a similar mechanism may be used by A. ferrooxidans in the reverse process, namely, to convey electrons from the oxidation of $\mathrm{Fe}$ (II) present in solid minerals to cells not in contact with the substrate.

Two additional ABC systems potentially involved in drug extrusion are also predicted in the genome, each associated with a HlyD secretion protein family (AFE2861-64, AFE1603-7). The first is directly downstream from the ars genes; the second cluster may have originated through lateral gene transfer since it is flanked by truncated transposases and hypothetical genes and it also exhibits anomalous $\mathrm{G}+\mathrm{C}$ content.

A. ferrooxidans may also be resistant to some antibiotics due to the presence of a two-gene cluster (AFE1977-78) potentially encoding a fosfomidocyn resistance protein and a TonB-family protein, respectively, and also a gene potentially encoding an AmpG permease protein (AFE1961).

\section{Stress responses}

For aerobically growing bacteria, the autooxidation of oxidases in the respiratory chain is the main source of endogenous reactive oxygen species (ROS). Increased levels of 
ROS can also result from exposure to redox active metals, including iron. Aerobic biomining microorganisms such as $A$. ferrooxidans that thrive in iron-rich environments are thus expected to be well equipped to deal with disturbances in oxidant-antiooxidant balance. Surprisingly, an unexpectedly low number of genes encoding known ROS detoxification functions were identified in the genome. These genes include a Mn-superoxide dismutase encoded by sodA (AFE1898), two non-identical copies of $a h p C$-like (AFE1468, AFE0985) and ahpD-like (AFE02014, AFE1814) members of the alkylhydroperoxidase family, and nox, (AFE1803) potentially encoding a NADH oxidase (FAD-dependent pyridine nucleotide-disulfide oxidoreductase family protein). This latter is considered to be important in oxygen scavenging in anaerobes because of its potential to reduce oxygen to water [115]. No genes coding for known catalases were detected.

On the other hand, A. ferrooxidans is predicted to have a complete set of components needed for non-enzymatic neutralization of ROS. This mechanism maintains high levels of low molecular weight thiols in the cytoplasm that, in combination with specific disulfide reductases, provide a reducing intracellular environment and maintain the thiol/disulfide balance of other molecules (unpublished results). Seven distinct thioredoxins (txr; AFE2867, AFE2848, AFE2590, AFE2362, AFE1979, AFE0657, AFE0047) and one thioredoxin disulfide reductase ( $\operatorname{tr} x B, A F E 0375)$ are present. Also present are the genes of the glutathione system necessary for glutathionetripeptide synthesis from the amino acids L-cysteine, Lglutamate, and glycine (gshA, AFE03064; gshB, AFE03063), four distinct glutaredoxins (gxr; AFE3038, AFE2449, AFE2263, AFE0367), and the glutathione reductase gorA (AFE0366).

In some bacteria, when basic protection is not sufficient, e.g., when sudden large increases in ROS occur, rapid global responses are induced to cope with the oxidative stress [116]. Often survival during the period of stress is aided by the simultaneous employment of multiple strategies. The strategies predicted to be available to A. ferrooxidans include repair of oxidative damage (e.g., $n f o$ ), bypassing of damaged functions (e.g., resistant isozymes acnA, fumC), and the exclusion of oxidative stress agents (e.g., $a c r A B$ multidrug efflux pump). Typically, many of these functions are coordinately regulated in response to superoxide by the SoxRS two-component regulator, and in response to peroxide by OxyR in Gram-negative bacteria or by PerR in Gram-positive bacteria. A. ferrooxidans lacks oxyR, soxR, and soxS orthologs, but has a Fur family regulator similar to PerR (AFE1467). The role of PerR in the control of $A$. ferrooxidans inducible stress response has not been investigated, but could include regulation of the divergently- transcribed AhpC family peroxidase (AFE1468). This arrangement is conserved in other microorganisms [117].

Other antioxidant defenses that are not controlled by the major oxidative stress regulators include the DNA repair enzyme endonuclease III (nth, AFE2682), glycoylases (mutM, AFE2758; mutY, AFE3015), DNA polymerase I (polA, AFE3094), recombinase protein A (recA, AFE0932), and other defenses including a peptide methionine sulfoxide reductase ( $m s r A B$, AFE2946-45) and a molecular chaperone ( $h l s O$, AFE1408).

\section{Flagella formation and chemotaxis}

Conserved fla or fla-related genes that could encode flagella were not identified in the genome, nor were che genes that encode classic chemotaxis functions. These observations conflict with Ohmura et al. (1996) [118] who proposed that the formation of flagella was a major factor mediating the adhesion of A. ferrooxidans ATCC 23270 to solid sulfur surfaces. This discrepancy could be explained if the fla genes have been lost in the particular culture used for sequencing. Since flagella genes are encoded in a multigene operon in many bacteria, their complete loss might require only one or a small number of excision events. In contrast, the multiple che genes are usually widely dispersed in bacterial genomes and their collective loss in $A$. ferrooxidans ATCC 23270 would presumably require multiple excision events. Alternative hypotheses to explain this discrepancy include (i) contamination of the A. ferrooxidans ATCC 23270 culture used by Ohmura et al. (1996) by a flagella-bearing microorganism, and (ii) significant differences between the culture used by Ohmura et al. (1996) and that used for our genome sequencing despite their identical designation (ATCC 23270).

\section{Adhesion and biofilm formation}

For mineral-associated bacteria, adhesion and biofilm formation are critical steps for colonization and subsequent mineral solubilization [119]. Cell surface structures such as pili have been shown to play a critical role in autoaggregation of microbial cells involved in biogeochemical processes [120]. A. ferrooxidans contains several gene clusters potentially involved in the formation of a type IV pilus (AFE0967-73, AFE0735-39, AFE0416, AFE0183-6, and AFE0006-7). Some of the relevant genes identified include those for the $\sigma_{54}$-dependent transcriptional regulator pilR (AFE0185) and for the signal transduction histidine kinase pils (AFE0184). In addition, candidate tad (tight adherence) genes (AFE2699-AFE2708) were also detected (Additional file 5). These genes are responsible for the secretion and assembly of bundled pili. In A. actinomycetemcomitans, they are essential for tight adherence, autoaggregation, and pili formation during colonization of dental surfaces [121]. They are also present in Thiomicrospora crunogena [88], a RISCs-oxidizing, chemoau- 
totrophic bacterium found in thermal vents. The multiple copies of genes for pili biosynthesis and adhesion in $A$. ferrooxidans could enable attachment and colonization on various mineral surfaces, such as pyrite, chalcopyrite, and solid sulfur. The redundancy of related regulatory genes could allow $A$. ferrooxidans to respond successfully to environmental changes.

Genes involved in quorum sensing that were previously identified and characterized include those that encode the classical autoinducer-binding transcriptional regulator LuxR (AFE1997) and the autoinducer synthesis protein LuxI (AFE1999) [122]. In addition, a second route for the production of homoserine lactones using the act system was predicted based on the presence of a gene encoding an acyltranferase (act, AFE2584) that was shown to be involved in the production of homoserine lactones of C14 length [123].

A five gene operon, containing luxA-galE-galK-pgm-galM, was assigned gene numbers AFE1341-45, respectively. This operon has been proposed to be involved in the formation of extra-cellular polysaccharide (EPS) precursors via the Leloir pathway [100]. GalU (AFE0445) and galTlike (AFE1237) have also been predicted to form part of the Leloir pathway and genes $r f b A, B, C$ and $D$ (AFE3295, AFE0441, AFE3294 and AFE0442, respectively) have been proposed to be involved in the biosynthesis of the EPS precursor dTDP-rhamnose. These groups of genes have been postulated to be involved in biofilm formation in $A$. ferrooxidans and their patterns of transcription were characterized in growth media with and without organic carbon supplementation [100].

\section{Genetic transfer}

A region of the genome (AFE1013-AFE1387, Figure 2) is enriched ( $84 \%$ versus $54 \%$ for the rest of the genome) in putative genes encoding hypothetical proteins, genes for DNA metabolism and sequences related to mobile elements such as transposases, plasmids, and bacteriophage (phage), and pseudogenes. The presence of site-specific recombinases and phage integrases in this region, as well as in other regions such as AFE2397-99, AFE0833-35 and AFE0507-9, indicates that $A$. ferrooxidans has been the target of phage infection. Although no phages are currently known to infect $A$. ferrooxidans, this finding suggests that further searching might be fruitful. Such phage could facilitate study of the mechanisms of viral infection in extremely acidic conditions, as well as serve as useful transducing agents for the genetic manipulation of $A$. ferrooxidans, as have been shown for the acidophilic archaeon, Sulfolobus spp. [124,125].
The genome contains clusters of genes whose sequence and gene order show significant similarity to both the Trb system of the Ri plasmid from Rhizobium rhizogenes and the Ti plasmid from Agrobacterium tumefaciens [126]. Most of these predicted genes potentially encode structural proteins of the type IV secretion system involved in conjugative DNA transfer. However, missing from the genome are the $t r b C, t r b H$, and $t r b K$ genes that encode an inner membrane lipoprotein, a pili structural protein, and a protein involved in plasmid immunity, respectively. Notably, one of two copies of a trbG-like gene is located within a highly conserved cluster in a position usually occupied by $t r b H$, and it may assume the role of this missing gene. The absence of critical components of the conjugation system suggests that $A$. ferrooxidans ATCC 23270 has lost the capacity to carry out conjugation via the Trb mechanism. The question arises as to the origin of the Ti plasmid-like sequences in A. ferrooxidans. One possibility is that it was acquired from an Agrobacterium-related microorganism or an ancestor of such through conjugation. A. ferrooxidans and a free-living or plant root-associated Agrobacterium might share the same environment at the interface of acidic drainages and anaerobic soils/water.

Ten proteins predicted to be involved in plasmid stability and maintenance are present in the genome. This discovery, coupled with the detection of an extensive suite of predicted conjugation-related genes, provides additional evidence that $A$. ferrooxidans was capable of undergoing conjugation. Even though no natural conjugation partners are known, conjugation between $E$. coli and A. ferrooxidans has been achieved in the laboratory. The frequency of detectable marker transfer has been very low $[95,127,128]$, and must be increased before this technique can be used for widespread genetic manipulation of A. ferrooxidans. Our finding of conjugation-related genes could stimulate further attempts.

Forty-one IS elements were identified, of which thirtythree could be classified as members of nine families according to the scheme of Mahillon and Chandler [129] (Additional file 3). The largest groups, designated here as ISafe3 (8 copies) and ISafe4 (3 copies), belong to the IS110 and IS3 families, respectively [129]. ISafe 1 , which is associated with phenotypic switching in A. ferrooxidans ATCC 19859 [130], was not detected in the genome of the type strain. Two non-identical copies of a Tn5468 transposon (family Tn7-like) were detected, each containing tnsABCDorf5 (AFE1201-AFE1205, AFE3199-95). The first copy is embedded in a suite of genes encoding hypothetical proteins; the second is associated with the atp operon and the glmSU as described for A. ferrooxidans ATCC 33020 [131]. 


\section{I. Predicted osmotic balance and potential $\mathrm{pH}$ tolerance mechanisms}

Acidophiles exhibit functional and structural properties that allow them to survive and proliferate in extremely acidic environments (pH 3 or below) [reviewed in 132]. These include: a) impermeable cell membranes (mostly in archaea); b) selective outer membrane porins; c) the generation of positive internal potential $(\Delta \psi)$ to create a chemosmotic barrier inhibiting proton influx; and d) the removal of excess internal protons by active proton pumping.

A putative gene (omp40, AFE2741) was identified that had significant similarity to an outer membrane porin found in A. ferrooxidans strain ATCC 19859 (133, 134). A large external, positively-charged loop has been predicted in Omp40 that may control pore size and ion selectivity at the porin entrance and may constitute a potential proton barrier $[133,134]$.

In addition, the following related functions were predicted (Additional file 3): several potassium transporters including one $\mathrm{K}+$ channel, one $\mathrm{K}+$ uptake protein and one $\mathrm{K}+$ efflux transporter; two copies of an ABC potassium import system that could be involved in the generation of a positive internal potential inhibiting proton influx; four $\mathrm{Na} / \mathrm{H}+$ antiporters and two proton P-type ATPases that could extrude excess internal protons. These predictions suggest specific areas for future experimental validation.

\section{Conclusion}

- Bioinformatics analysis of the complete genome of the type strain of $A$. ferrooxidans (ATCC 23207) provides a valuable platform for gene discovery and functional prediction that is especially important given the difficulties in carrying out standard genetic research in this microorganism. The models presented herein should facilitate the design and interpretation of future experiments and enable the experimental investigator to focus on important issues.

- An analysis of the genome of the type strain provides a coherent view of the gene content and metabolic potential of this species (Figure 7).

- Metabolic models support the key capabilities of A. ferrooxidans that pertain to its use in industrial bioleaching, including its ability to oxidize both sulfur and iron, to resist low $\mathrm{pH}$, and to live in environments with potentially toxic organic and inorganic chemicals. They also suggest that it has the ability to precipitate metals in anaerobic environments, which would be deleterious to copper bioleaching activity.

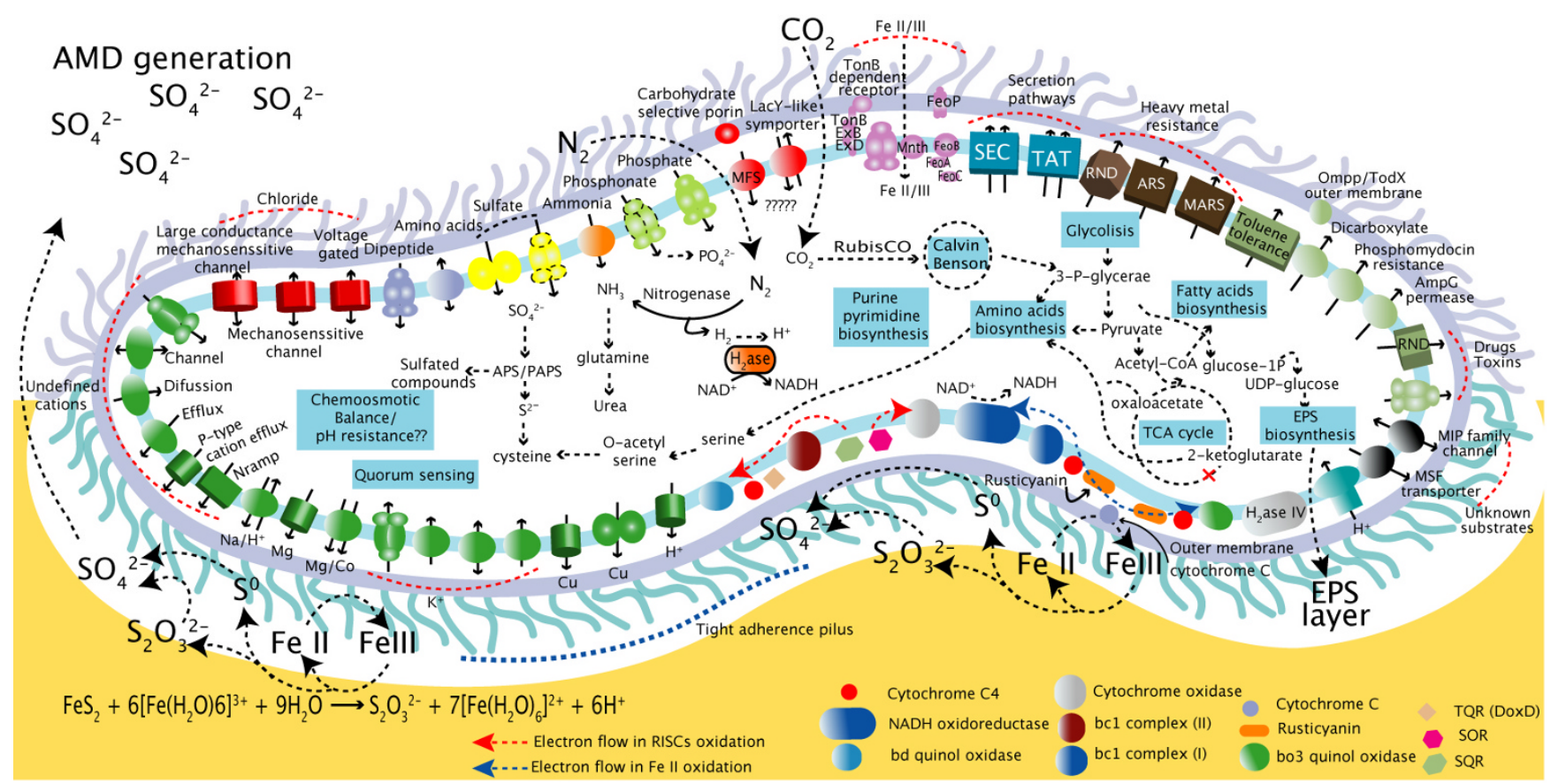

Figure 7

Whole-cell model for A. ferrooxidans ATCC 23270. Genome-based model of the cellular metabolism of $A$. ferrooxidans including predicted transport systems; chemolithoautotrophic components; carbon, nitrogen and sulfur metabolism; and biogeochemical cycling. 
- Our analysis also prompts several unexpected predictions, some of which could potentially be useful in biomining such as the proposed connection between biofilm formation and central carbon metabolism and the presence of several predicted quorum sensing mechanisms. Indications of past phage infection and conjugation events suggest potentially fruitful approaches for the development of efficient methods for genetic manipulation of this microorganism.

- Metabolic models also indicate how this microorganism could play an important role as a producer of fixed carbon and nitrogen and as a recycler of metals in bioleaching operations as well as in natural environments.

\section{Methods}

\section{Genome sequencing and assembly}

The genome was sequenced and assembled using the whole genome shotgun method as previously described [135-137].

\section{Sequence annotation}

Gene modeling was performed using CRTICA [138] and GLIMMER [139]. The lists of open reading frames (ORFs) generated by both strategies were merged using CRITICA start sites when models were identical. The translated ORFs were submitted to BLAST analysis against the UNIPROT database to evaluate overlaps and alternative start sites. The final list of coding sequences (CDSs) was translated, and these amino acid sequences were then used to query the following databases (August-December, 2007): National Center for Biotechnology Information (NCBI) nonredundant database, UniProt, TIGRFam, Pfam, PRIAM, KEGG, COG, and InterPro. Manual functional assignments were performed gene-by-gene, when needed. Comparative genome analyses were also performed using the Comprehensive Microbial Resource [140].

\section{Nucleotide sequence accession numbers}

The sequence and annotation of the complete A. ferrooxidans strain ATCC 23270 genome is available at the Comprehensive Microbial Resource (CMR) (J. Craig Venter Institute, http://www.jcvi.org) and in GenBank/EMBL/ DDBJ accession number CP001219.

\section{Authors' contributions}

JE and DH proposed the study; RB provided the DNA; JE, $\mathrm{RD}$ and HT were responsible for the genome sequencing and assembly; all authors contributed to the annotation; $\mathrm{JV}$ was responsible for the metabolic reconstruction with contributions from RQ, IP and DH; JV and DH drafted the manuscript; all authors read and approved the final manuscript.

\section{Additional material}

\section{Additional file 1}

Gene lists for amino acid metabolism, cofactor biosynthesis and purine and pyrimidine metabolism. A list of genes in the A. ferrooxidans ATCC 23270 genome is provided that are predicted to be involved in amino acid metabolism, cofactor biosynthesis and purine and pyrimidine metabolism.

Click here for file

[http://www.biomedcentral.com/content/supplementary/14712164-9-597-S1.xls]

\section{Additional file 2}

Phylogram of four different Rubisco enzymes in various bacteria. Phylogenetic tree of forms I (CbbL1,CbbL2), II (CbbM), and IV (RLP, Rubisco-like protein) of the large subunit of ribulose-1,5-bisphosphate carboxylase/oxygenase (RubisCO) from various organisms. The multiple sequence alignments and trees were produced with ClustalW and visualized with MEGA. Bootstrap values indicated at the nodes are based on 1,000 trials. The RubisCOs from A. ferrooxidans are highlighted by blue boxes. Species names are as follows: Archaeoglobus fulgidus, Bacillus subtilis, Chlorobium limicola, Chlorobium tepidum, Hydrogenovibrio marinus, Ralstonia eutropha, Rhodobacter capsulatus, Rhodobacter sphaeroides, Rhodopseudomonas palustris,

Rhodospirilum rubrum, Synechococcus $s p$. PCC6301, Thiobacillus intermedius, and Thiobacillus neapolitanus.

Click here for file

[http://www.biomedcentral.com/content/supplementary/1471-

2164-9-597-S2.png]

\section{Additional file 3}

Gene lists and predicted properties for several metabolic and cellular processes. This data provides a list of genes and predicted properties for transposase families, hydrogenase systems, nutrient transport systems, osmotic balance, heavy metal resistance systems and toxic organic compounds extrusion systems deduced from the A. ferrooxidans ATCC 23270 genome sequence.

Click here for file

[http://www.biomedcentral.com/content/supplementary/14712164-9-597-S3.pdf]

\section{Additional file 4}

Gene clusters predicted to be involved in nitrogen metabolism. This data provides a schematic representation of some of the gene clusters and genes predicted to be involved in nitrogen fixation.

Click here for file

[http://www.biomedcentral.com/content/supplementary/1471-

2164-9-597-S4.pdf]

\section{Additional file 5}

Genes predicted to be involved type IV pilus formation. This data provides a list of genes predicted to be involved type IV pilus formation. Click here for file

[http://www.biomedcentral.com/content/supplementary/14712164-9-597-S5.pdf]

\section{Acknowledgements}

We thank Joel Malek, the laboratory, IT and Bioinformatics staff at The Institute for Genomic Research (now incorporated within the JC Venter Institute) for assistance with sequencing and analysis. Work supported by 
Fondecyt 1050063, Fondecyt I I 060 I64, DI-UNAB 34-06, DI-UNAB |5-06/ $\mathrm{I}$, and a Microsoft Sponsored Research Award. The sequencing and annotation was supported by the U.S. Department of Energy, Office of Biological Energy Research, Cooperative Agreement DE-FC02-95ER61962 to TIGR.

\section{References}

I. Rohwerder T, Gehrke T, Kinzler K, Sand W: Bioleaching review part A: progress in bioleaching: fundamentals and mechanisms of bacterial metal sulfide oxidation. Appl Microbiol Biotechnol 2003, 63(3):239-248.

2. Gonzalez-Toril E, Llobet-Brossa E, Casamayor EO, Amann R, Amils $R$ : Microbial ecology of an extreme acidic environment, the Tinto River. Appl Environ Microbiol 2003, 69(8):4853-4865.

3. Davis RA Jr, Welty AT, Borrego J, Morales JA, Pendon JG, Ryan JG: Rio Tinto estuary (Spain): $\mathbf{5 0 0 0}$ years of pollution. Environmental Geology 2000, 39(10): I 107-III6.

4. Rawlings DE: Heavy metal mining using microbes. Annu Rev Microbiol 2002, 56:65-91.

5. Levican G, Bruscella P, Guacunano M, Inostroza C, Bonnefoy V, Holmes DS, Jedlicki E: Characterization of the petl and res operons of Acidithiobacillus ferrooxidans. J Bacteriol 2002, I84(5): I 498-I50I.

6. Yarzabal A, Appia-Ayme C, Ratouchniak J, Bonnefoy V: Regulation of the expression of the Acidithiobacillus ferrooxidans rus operon encoding two cytochromes c, a cytochrome oxidase and rusticyanin. Microbiology 2004, I 50(Pt 7):2I |3-2I 23.

7. Brasseur G, Levican G, Bonnefoy V, Holmes D, Jedlicki E, LemesleMeunier D: Apparent redundancy of electron transfer pathways via bc(I) complexes and terminal oxidases in the extremophilic chemolithoautotrophic Acidithiobacillus ferrooxidans. Biochim Biophys Acta 2004, 1656(2-3): | | 4-126.

8. Bruscella P, Appia-Ayme C, Levican G, Ratouchniak J, Jedlicki E, Holmes DS, Bonnefoy V: Differential expression of two bcl complexes in the strict acidophilic chemolithoautotrophic bacterium Acidithiobacillus ferrooxidans suggests a model for their respective roles in iron or sulfur oxidation. Microbiology 2007, I 53(Pt I): 102-1 I0.

9. Drobner E, Huber H, Stetter KO: Thiobacillus ferrooxidans, a facultative hydrogen oxidizer. Appl Environ Microbiol 1990 56(9):2922-2923.

10. Pronk JT, Meijer WM, Hazeu W, van Dijken JP, Bos P, Kuenen JG: Growth of Thiobacillus ferrooxidans on Formic Acid. Appl Environ Microbiol I99I, 57(7):2057-2062.

II. Duquesne K, Lebrun S, Casiot C, Bruneel O, Personne JC, Leblanc M, Elbaz-Poulichet F, Morin G, Bonnefoy V: Immobilization of arsenite and ferric iron by Acidithiobacillus ferrooxidans and its relevance to acid mine drainage. Appl Environ Microbiol 2003 69(10):6165-6173.

12. Sugio T, Domatsu C, Munakata O, Tano T, Imai K: Role of a Ferric Ion-Reducing System in Sulfur Oxidation of Thiobacillus ferrooxidans. Appl Environ Microbiol I985, 49(6): | 40। - 406

13. $\mathrm{Ng} \mathrm{KY}$, Sawada R, Inoue S, Kamimura K, Sugio T: Purification and some properties of sulfur reductase from the iron-oxidizing bacterium Thiobacillus ferrooxidans NASF-I. J Biosci Bioeng 2000, 90(2):199-203.

14. Heinhorst S, Baker SH, Johnson DR, Davies PS, Cannon GC, Shively JM: Two Copies of form I RuBisCO genes in Acidithiobacillus ferrooxidans ATCC 23270. Curr Microbiol 2002, 45(2): I I - I I 7 .

15. Makcintosh MW: Nitrogen fixation by Thiobacillus ferrooxidans. J Gen Microbiol 1978, 34(105):215-2 I8.

16. Pretorius IM, Rawlings DE, Woods DR: Identification and cloning of Thiobacillus ferrooxidans structural nif genes in Escherichic coli. Gene 1986, 45(I):59-65.

17. Rowe OF, Sanchez-Espana J, Hallberg KB, Johnson DB: Microbial communities and geochemical dynamics in an extremely acidic, metal-rich stream at an abandoned sulfide mine (Huelva, Spain) underpinned by two functional primary production systems. Environ Microbiol 2007, 9(7): |76|-I77|.

18. Dietrich LE, Tice MM, Newman DK: The co-evolution of life and Earth. Curr Biol 2006, I6( I I):R395-400.

19. Gonzalez-Toril E, Martinez-Frias J, Gomez Gomez JM, Rull F, Amils R: Iron meteorites can support the growth of acidophilic chemolithoautotrophic microorganisms. Astrobiology 2005, 5(3):406-414.
20. Nealson $\mathrm{KH}$, Saffarini D: Iron and manganese in anaerobic respiration: environmental significance, physiology, and regulation. Annu Rev Microbiol 1994, 48:3 I I-343.

21. Quatrini R, Lefimil C, Holmes DS, Jedlicki E: The ferric iron uptake regulator (Fur) from the extreme acidophile Acidithiobacillus ferrooxidans. Microbiology 2005, I 5 I (Pt 6):2005-20I5.

22. Quatrini R, Jedlicki E, Holmes DS: Genomic insights into the iron uptake mechanisms of the biomining microorganism Acidithiobacillus ferrooxidans. I Ind Microbiol Biotechnol 2005, 32(I I-I 2):606-6I4.

23. Selkov E, Overbeek R, Kogan Y, Chu L, Vonstein V, Holmes D, Silver $\mathrm{S}$, Haselkorn R, Fonstein M: Functional analysis of gapped microbial genomes: amino acid metabolism of Thiobacillus ferrooxidans. Proc Natl Acad Sci USA 2000, 97(7):3509-35।4.

24. Rawlings DE: The evolution of pTF-FC2 and PTC-FI4, two related plasmids of the IncQ-family. Plasmid 2005, 53(2): $137-147$

25. Nuñez $\mathrm{H}$, Lefimil $\mathrm{C}$, Min B, Soll D, Orellana O: In vivo formation of glutamyl-tRNA(GIn) in Escherichia coli by heterologous glutamyl-tRNA synthetases. FEBS Lett 2004, 557( I-3): I33-135.

26. Levican G, Katz A, de Armas M, Nunez H, Orellana O: Regulation of a glutamyl-tRNA synthetase by the heme status. Proc Nat Acad Sci USA 2007, 104(9):3135-3140.

27. Ohmura N, Matsumoto N, Sasaki K, Saiki H: Electrochemical regeneration of $\mathrm{Fe}(\mathrm{III})$ to support growth on anaerobic iron respiration. Appl Environ Microbiol 2002, 68(I):405-407.

28. Holmes D, Bonnefoy V: Insights into Iron and Sulfur Oxidation Mechanisms of Bioleaching Organisms. In Biomining Edited by: Rawlings DE, Johnson BD. Berlin: Springer-Verlag; 2006:28I-307.

29. Gale NL, Beck JV: Evidence for the Calvin cycle and hexose monophosphate pathway in Thiobacillus ferrooxidans. I Bacteriol 1967, 94(4): 1052-1059.

30. Silver M: Oxidation of elemental sulfur and sulfur compounds and $\mathrm{CO} 2$ fixation by Ferrobacillus ferrooxidans (Thiobacillus ferrooxidans). Can J Microbiol 1970, I6(9):845-849.

31. Tabita FR: Molecular and cellular regulation of autotrophic carbon dioxide fixation in microorganisms. Microbiol Rev 1988 52(2): $155-189$

32. Pulgar V, Gaete L, Allende J, Orellana O, Jordana X, Jedlicki E: Isolation and nucleotide sequence of the Thiobacillus ferrooxidans genes for the small and large subunits of ribulose 1,5bisphosphate carboxylase/oxygenase. FEBS Lett I991, 292(I2):85-89.

33. Kusano T, Takeshima T, Inoue C, Sugawara K: Evidence for two sets of structural genes coding for ribulose bisphosphate carboxylase in Thiobacillus ferrooxidans. J Bacteriol 1991, 173(22):73|3-7323.

34. Quatrini R, Appia-Ayme C, Denis C, Ratouchniak J, Veloso F, Valdes J, Lefimil C, Silver S, Roberto F, Orellana O, et al: Insights into the Iron and Sulfur Energetic Metabolism of Acidthiobacillus ferrooxidans by Microarray Transcriptome Profiling. Hydrometallurgy 2006, 83:263-272.

35. Imker HJ, Fedorov AA, Fedorov EV, Almo SC, Gerlt JA: Mechanistic diversity in the RuBisCO superfamily: the "enolase" in the methionine salvage pathway in Geobacillus kaustophilus. Biochemistry 2007, 46(13):4077-4089.

36. Yoshizawa $\mathrm{Y}$, Toyoda $\mathrm{K}$, Arai H, Ishii M, Igarashi Y: CO2-responsive expression and gene organization of three ribulose-I,5bisphosphate carboxylase/oxygenase enzymes and carboxysomes in Hydrogenovibrio marinus strain MH-II0. J Bacteriol 2004, I 86( I 7):5685-569|.

37. Straub KL, Rainey FA, Widdel F: Rhodovulum iodosum sp. nov. and Rhodovulum robiginosum sp. nov., two new marine phototrophic ferrous-iron-oxidizing purple bacteria. Int / Syst Bacteriol 1999, 49(Pt 2):729-735.

38. Jiao $Y$, Newman DK: The pio operon is essential for phototrophic $\mathrm{Fe}$ (II) oxidation in Rhodopseudomonas palustris TIE-I. J Bacteriol 2007, I89(5): 1765-1773.

39. Croal LR, Jiao Y, Newman DK: The fox operon from Rhodobacter strain SW2 promotes phototrophic Fe(II) oxidation in Rhodobacter capsulatus SBI003. I Bacteriol 2007, 189(5): I774-| 782.

40. Appia-Ayme C, Guiliani N, Ratouchniak J, Bonnefoy V: Characterization of an operon encoding two c-type cytochromes, an aa(3)-type cytochrome oxidase, and rusticyanin in Thiobacil- 
lus ferrooxidans ATCC 33020. Appl Environ Microbiol 1999 65(II):478I-4787.

41. Yarzabal A, Brasseur G, Ratouchniak J, Lund K, Lemesle-Meunier D, DeMoss JA, Bonnefoy V: The high-molecular-weight cytochrome c Cyc2 of Acidithiobacillus ferrooxidans is an outer membrane protein. J Bacteriol 2002, I 84(I):3|3-3I7.

42. Castelle C, Guiral M, Malarte G, Ledgham F, Leroy G, Brugna M, Giudici-Orticoni MT: A new Fe-oxidizing/O2-reducing supercomplex spanning both inner and outer membranes, isolated from the extreme acidophile Acidithiobacillus ferrooxidans. J Biol Chem in press.

43. Fukumori $F$, Yano T, Sato A, Yamanaka T: Fe(II)-oxidizing enzyme purified from Thiobacillus ferrooxidans. FEMS Microbiology Letters 1988, 50(2-3):169-172.

44. Cavazza C, Guigliarelli B, Bertrand P, Bruschi M: Biochemical and EPR characterization of a high potential iron-sulfur protein in Thiobacillus ferrooxidans. FEMS Microbiology Letters 1995, 130(2-3): 193-199.

45. Bruscella P, Cassagnaud L, Ratouchniak J, Brasseur G, Lojou E, Amils R, Bonnefoy V: The HiPIP from the acidophilic Acidithiobacillus ferrooxidans is correctly processed and translocated in Escherichia coli, in spite of the periplasm $\mathrm{pH}$ difference between these two micro-organisms. Microbiology 2005, I5 I(Pt 5): |42|-|43|

46. Quatrini R, Appia-Ayme C, Denis Y, Ratouchniak J, Veloso F, Valdes J, Lefimil C, Silver S, Roberto F, Orellana O, et al.: Global analysis of the ferrous iron and sulfur energetic metabolism of Acidithiobacillus ferrooxidans by microarray transcriptome profiling. In 16th International Biohydrometallurgy Symposium: 2005 Cape Town, South Africa: elsevier; 2005:761-77I.

47. Kusano T, Takeshima T, Sugawara K, Inoue C, Shiratori T, Yano T, Fukumori Y, Yamanaka T: Molecular cloning of the gene encoding Thiobacillus ferrooxidans Fe(II) oxidase. High homology of the gene product with HiPIP. I Biol Chem 1992, 267( I6): I I242-I I 247.

48. Pronk JT, Meulemberg R, Hazeu W, Bos P, Kuenen JG: Oxidation of reduced inorganic sulphur compounds by acidophilic thiobacilli. FEMS Microbiology letters 1990, 75(2-3):293-306.

49. Wakai $S$, Kikumoto M, Kanao T, Kamimura $K$ : Involvement of sulfide:quinone oxidoreductase in sulfur oxidation of an acidophilic iron-oxidizing bacterium, Acidithiobacillus ferrooxidans NASF-I. Biosci Biotechnol Biochem 2004, 68( I 2):2519-2528.

50. Wakai S, Tsujita M, Kikumoto M, Manchur MA, Kanao T, Kamimura $\mathrm{K}$ : Purification and characterization of sulfide:quinone oxidoreductase from an acidophilic iron-oxidizing bacterium, Acidithiobacillus ferrooxidans. Biosci Biotechnol Biochem 2007, 7 I(I I):2735-2742.

5I. Kanao T, Kamimura K, Sugio T: Identification of a gene encoding a tetrathionate hydrolase in Acidithiobacillus ferrooxidans. J Biotechnol 2007, I32(I): 16-22.

52. Purschke WG, Schmidt CL, Petersen A, Schafer G: The terminal quinol oxidase of the hyperthermophilic archaeon Acidianus ambivalens exhibits a novel subunit structure and gene organization. J Bacteriol 1997, I79(4): I344-I 353.

53. Muller FH, Bandeiras TM, Urich T, Teixeira M, Gomes CM, Kletzin A Coupling of the pathway of sulphur oxidation to dioxygen reduction: characterization of a novel membrane-bound thiosulphate:quinone oxidoreductase. Mol Microbiol 2004 53(4): I I47-II 60

54. Tabita R, Silver M, Lundgren DG: The rhodanese enzyme of Ferrobacillus ferrooxidans (Thiobacillus ferrooxidans). Can J Biochem 1969, 47( I 2): I|4|-||45.

55. Acosta M, Beard S, Ponce J, Vera M, Mobarec JC, Jerez CA: Identification of putative sulfurtransferase genes in the extremophilic Acidithiobacillus ferrooxidans ATCC 23270 genome: structural and functional characterization of the proteins. Omics 2005, 9(I):13-29.

56. Silver M, Lundgren DG: sulfur-oxidizing enzyme of Ferrobacillus ferrooxidans (Thiobacillus ferrooxidans). Can J Biochem 1968, 46:457-46I.

57. Vestal JR, Lundgren DG: The sulfite oxidase of Thiobacillus ferrooxidans (Ferrobacillus ferrooxidans). Can J Biochem 1971, 49(10): I I 25- II 30.

58. Fischer J, Quentmeier A, Kostka S, Kraft R, Friedrich CG: Purification and characterization of the hydrogenase from Thiobacillus ferrooxidans. Arch Microbiol 1996, 165(5):289-296.
59. Vignais PM, Billoud B, Meyer J: Classification and phylogeny of hydrogenases. FEMS Microbiol Rev 200I, 25(4):455-50I.

60. Sargent F, Berks BC, Palmer T: Assembly of membrane-bound respiratory complexes by the Tat protein-transport system. Arch Microbiol 2002, 178(2):77-84.

6I. Friedrich CG, Bardischewsky F, Rother D, Quentmeier A, Fischer ]: Prokaryotic sulfur oxidation. Curr Opin Microbiol 2005, 8(3):253-259

62. Appel J, Phunpruch S, Steinmuller K, Schulz R: The bidirectional hydrogenase of Synechocystis sp. PCC $\mathbf{6 8 0 3}$ works as an electron valve during photosynthesis. Arch Microbiol 2000, I73(56):333-338.

63. Schroder O, Bleijlevens B, de Jongh TE, Chen Z, Li T, Fischer J, Forster J, Friedrich CG, Bagley KA, Albracht SP, et al:: Characterization of a cyanobacterial-like uptake [NiFe] hydrogenase: EPR and FTIR spectroscopic studies of the enzyme from Acidithiobacillus ferrooxidans. J Biol Inorg Chem 2007, I 2(2):2 I2-233

64. Schwartz E, Buhrke T, Gerischer U, Friedrich B: Positive transcriptional feedback controls hydrogenase expression in Alcaligenes eutrophus HI6. J Bacteriol 1999, I 8 I ( I 8):5684-5692.

65. Dischert W, Vignais PM, Colbeau A: The synthesis of Rhodobacter capsulatus HupSL hydrogenase is regulated by the two-component HupT/HupR system. Mol Microbiol I999, 34(5):995- 1006.

66. Lenz $O$, Friedrich $B$ : A novel multicomponent regulatory system mediates $\mathbf{H} 2$ sensing in Alcaligenes eutrophus. Proc Nat Acad Sci USA 1998, 95(2 I): 12474- 2479.

67. van Soom C, Lerouge I, Vanderleyden J, Ruiz-Argueso T, Palacios JM: Identification and characterization of hupT, a gene involved in negative regulation of hydrogen oxidation in Bradyrhizobium japonicum. Jacteriol I999, I 8 I ( I6):5085-5089.

68. Valdes J, Veloso F, Jedlicki E, Holmes D: Metabolic reconstruction of sulfur assimilation in the extremophile Acidithiobacillus ferrooxidans based on genome analysis. BMC Genomics 2003, 4(1):5I.

69. Ma K, Adams MW: Sulfide dehydrogenase from the hyperthermophilic archaeon Pyrococcus furiosus: a new multifunctional enzyme involved in the reduction of elemental sulfur. J Bacteriol 1994, 176(21):6509-65I7.

70. Hedderich R: Energy-converting [NiFe] hydrogenases from archaea and extremophiles: ancestors of complex I. J Bioenerg Biomembr 2004, 36(I):65-75.

7I. Meuer J, Kuettner HC, Zhang JK, Hedderich R, Metcalf WW: Genetic analysis of the archaeon Methanosarcina barkeri Fusaro reveals a central role for Ech hydrogenase and ferredoxin in methanogenesis and carbon fixation. Proc Natl Acad Sci USA 2002, 99(8):5632-5637.

72. Brasseur G, Bruscella P, Bonnefoy V, Lemesle-Meunier D: The bc(I) complex of the iron-grown acidophilic chemolithotrophic bacterium Acidithiobacillus ferrooxidans functions in the reverse but not in the forward direction. Is there a second bc(I) complex? Biochim Biophys Acta 2002, I 555(I-3):37-43.

73. Andrews SC, Berks BC, McClay J, Ambler A, Quail MA, Golby P, Guest JR: A I 2-cistron Escherichia coli operon (hyf) encoding a putative proton-translocating formate hydrogenlyase system. Microbiology 1997, I43(Pt I I):3633-3647.

74. Ohmura N, Sasaki K, Matsumoto N, Saiki H: Anaerobic respiration using $\mathrm{Fe}(3+), \mathbf{S}(0)$, and $\mathbf{H}(2)$ in the chemolithoautotrophic bacterium Acidithiobacillus ferrooxidans. I Bacteriol 2002, 184(8):208|-2087.

75. Pronk JT, de Bruyn JC, Bos P, Kuenen JG: Anaerobic Growth of Thiobacillus ferrooxidans. Appl Environ Microbiol 1992 58(7):2227-2230.

76. Yarzabal A, Brasseur G, Bonnefoy V: Cytochromes c of Acidithiobacillus ferrooxidans. FEMS Microbiol Lett 2002, 209(2): 189-195.

77. Sugio T, Mizunashi W, Inagaki K, Tano T: Purification and some properties of sulfur:ferric ion oxidoreductase from Thiobacillus ferrooxidans. J Bacteriol 1987, I69(II):4916-4922.

78. Sugio T, Hirose T, Ye LZ, Tano T: Purification and some properties of sulfite:ferric ion oxidoreductase from Thiobacillus ferrooxidans. J Bacteriol 1992, 174(12):4189-4192.

79. $\mathrm{Ng} \mathrm{KY}$, Sawada R, Inoue S, Kamimura K, Sugio T: Purification and some properties of sulfur reductase from the iron-oxidizing bacterium Thiobacillus ferrooxidans NASF-I. J Biosci Bioeng 2000, 90(2):199-203 
80. Laska S, Lottspeich F, Kletzin A: Membrane-bound hydrogenase and sulfur reductase of the hyperthermophilic and acidophilic archaeon Acidianus ambivalens. Microbiology 2003, I49(Pt 9):2357-237I.

81. Pretorius IM, Rawlings DE, Woods DR: Identification and cloning of Thiobacillus ferrooxidans structural nif genes in Escherichia coli. Gene 1986, 45(I):59-65.

82. Pretorius IM, Rawlings DE, O'Neill EG, Jones WA, Kirby R, Woods DR: Nucleotide sequence of the gene encoding the nitrogenase iron protein of Thiobacillus ferrooxidans. J Bacteriol 1987, I 69(I):367-370.

83. Rawlings DE: Sequence and structural analysis of the alphaand beta-dinitrogenase subunits of Thiobacillus ferrooxidans. Gene 1988, 69(2):337-343.

84. Dixon R, Kahn D: Genetic regulation of biological nitrogen fixation. Nat Rev Microbiol 2004, 2(8):62 I-63I.

85. Little R, Martinez-Argudo I, Dixon R: Role of the central region of NifL in conformational switches that regulate nitrogen fixation. Biochem Soc Trans 2006, 34(Pt I): I62-164.

86. Forchhammer K: $\mathbf{P}$ (II) signal transducers: novel functional and structural insights. Trends Microbiol 2008, I 6(2):65-72.

87. Ishida ML, Assumpcao MC, Machado HB, Benelli EM, Souza EM, Pedrosa FO: Identification and characterization of the two-component NtrY/NtrX regulatory system in Azospirillum brasilense. Braz J Med Biol Res 2002, 35(6):65 I-66I.

88. Scott KM, Sievert SM, Abril FN, Ball LA, Barrett CJ, Blake RA, Boller AJ, Chain PS, Clark JA, Davis CR, et al.: The genome of deep-sea vent chemolithoautotroph Thiomicrospira crunogena XCL-2. PLoS Biol 2006, 4( I 2):e383.

89. Felce J, Saier MH Jr: Carbonic anhydrases fused to anion transporters of the SulP family: evidence for a novel type of bicarbonate transporter. J Mol Microbiol Biotechnol 2004, 8(3): I69-I 76.

90. Seeger $M$, Jerez CA: Phosphate-starvation induced changes in Thiobacillus ferrooxidans. FEMS Microbiol Lett 1993, 108(I):35-4I.

91. Alvarez S, Jerez CA: Copper ions stimulate polyphosphate degradation and phosphate efflux in Acidithiobacillus ferrooxidans. Appl Environ Microbiol 2004, 70(9):5177-5। 82

92. Vera M, Pagliai F, Guiliani N, Jerez CA: The chemolithoautotroph Acidithiobacillus ferrooxidans can survive under phosphatelimiting conditions by expressing a C-P lyase operon that allows it to grow on phosphonates. Appl Environ Microbiol 2008, 74(6): | 829-1835.

93. Quatrini R, Lefimil C, Veloso FA, Pedroso I, Holmes DS, Jedlicki E: Bioinformatic prediction and experimental verification of Fur-regulated genes in the extreme acidophile Acidithiobacillus ferrooxidans. Nucleic Acids Res 2007, 35(7):2I53-2I66.

94. Osorio H, Martínez V, Nieto PA, Holmes DS, Quatrini R: Microbial iron management mechanisms in extremely acidic environments: comparative genomics evidence for diversity and versatility. BMC Microbiology 2008, 8(I):203.

95. Liu Z, Borne F, Bonnefoy V: Genetic transfer of IncP, IncQ and IncW plasmids to four Thiobacillus ferrooxidans strains by conjugation. Hydrometallurgy 200I, 59:339-345.

96. Beller HR, Letain TE, Chakicherla A, Kane SR, Legler TC, Coleman MA: Whole-genome transcriptional analysis of chemolithoautotrophic thiosulfate oxidation by Thiobacillus denitrificans under aerobic versus denitrifying conditions. J Bacteriol 2006, I 88(19):7005-7015

97. Ward N, Larsen O, Sakwa J, Bruseth L, Khouri H, Durkin AS, Dimitrov G, Jiang L, Scanlan D, Kang KH, et al.: Genomic insights into methanotrophy: the complete genome sequence of Methylococcus capsulatus (Bath). PLoS Biol 2004, 2( I 0): e303.

98. Chain P, Lamerdin J, Larimer F, Regala W, Lao V, Land M, Hauser L, Hooper A, Klotz M, Norton J, et al.: Complete genome sequence of the ammonia-oxidizing bacterium and obligate chemolithoautotroph Nitrosomonas europaea. J Bacteriol 2003 , I 85(9):2759-2773.

99. Klotz MG, Arp DJ, Chain PS, El-Sheikh AF, Hauser LJ, Hommes NG Larimer FW, Malfatti SA, Norton JM, Poret-Peterson AT, et al.: Complete genome sequence of the marine, chemolithoautotrophic, ammonia-oxidizing bacterium Nitrosococcus oceani ATCC 19707. Appl Environ Microbiol 2006 72(9):6299-6315.

100. Barreto M, Jedlicki E, Holmes DS: Identification of a gene cluster for the formation of extracellular polysaccharide precursors in the chemolithoautotroph Acidithiobacillus ferrooxidans. Appl Environ Microbiol 2005, 7 I (6):2902-2909.

10I. Boel G, Mijakovic I, Maze A, Poncet S, Taha MK, Larribe M, Darbon E, Khemiri A, Galinier A, Deutscher J: Transcription regulators potentially controlled by HPr kinase/phosphorylase in Gramnegative bacteria. J Mol Microbiol Biotechnol 2003, 5(4):206-2I5.

102. Deutscher J, Francke C, Postma PW: How phosphotransferase system-related protein phosphorylation regulates carbohydrate metabolism in bacteria. Microbiol Mol Biol Rev 2006, 70(4):939-1031.

103. Appia-Ayme C, Quatrini R, Dennis Y, Denizot F, Silver S, Roberto F, Veloso F, Valdes J, Cardenas J, Esparza M, et al.: Microarray and bioinformatic analyses suggest models for carbon metabolism in the autotroph Acidithiobacillus ferrooxidans. Hydrometallurgy 2006, 83(I-4):273-280.

104. Wood AP, Aurikko JP, Kelly DP: A challenge for 2 I st century molecular biology and biochemistry: what are the causes of obligate autotrophy and methanotrophy? FEMS Microbiol Rev 2004, 28(3):335-352

105. Silver S, Phung le T: A bacterial view of the periodic table: genes and proteins for toxic inorganic ions. J Ind Microbiol Biotechnol 2005, 32(I I-1 2):587-605.

106. Butcher BG, Rawlings DE: The divergent chromosomal ars operon of Acidithiobacillus ferrooxidans is regulated by an atypical ArsR protein. Microbiology 2002, 148 (Pt I 2):3983-3992.

107. Butcher BG, Deane SM, Rawlings DE: The chromosomal arsenic resistance genes of Thiobacillus ferrooxidans have an unusual arrangement and confer increased arsenic and antimony resistance to Escherichia coli. Appl Environ Microbiol 2000, 66(5): 1826-1833.

108. Olson GJ, Porter FD, Rubinstein J, Silver S: Mercuric reductase enzyme from a mercury-volatilizing strain of Thiobacillus ferrooxidans. J Bacteriol I982, I5 I(3): I230-1236.

109. Takeuchi F, Negishi A, Nakamura S, Kanao T, Kamimura K, Sugio T: Existence of an iron-oxidizing bacterium Acidithiobacillus ferrooxidans resistant to organomercurial compounds. J Biosci Bioeng 2005, 99(6):586-59।.

II0. Takeuchi F, Sugio T: Volatilization and recovery of mercury from mercury-polluted soils and wastewaters using mercury-resistant Acidithiobacillus ferrooxidans strains SUG 2-2 and MON-I. Environ Sci 2006, I3(6):305-316.

III. Barreto M, Quatrini R, Bueno S, Arriagada C, Valdes J, Silver S, Jedlicki E, Holmes D: Aspects of the predicted physiology of Acidithiobacillus ferrooxidans deduced from an analysis of its partial genome sequence. Hydrometallurgy 2003, 7 I (I-2):97-I05.

1 12. Nicomrat D, Dick WA, Tuovinen $\mathrm{OH}$ : Microbial populations identified by fluorescence in situ hybridization in a constructed wetland treating acid coal mine drainage. I Environ Qual 2006, 35(4): I329-1337.

I 13. Dold B, Blowes D, Dickhout R, Spangenberg J, Pfeifer H: Low molecular weight carboxylic acids in oxidizing porphyry copper tailings. Environ Sci Technol 2005, 39(8):25I 5-252I.

114. Newman DK: From iron oxides to infections. Geobiology 2008 6(3): $196-200$

I15. Kawasaki S, Ishikura J, Chiba D, Nishino T, Niimura Y: Purification and characterization of an H2O-forming NADH oxidase from Clostridium aminovalericum: existence of an oxygendetoxifying enzyme in an obligate anaerobic bacteria. Arch Microbiol 2004, I 81:324-330.

116. Zheng M, Doan B, Schneider T, Storz G: OxyR and SoxRS regulation of fur. J Bacteriol 1999, 181:4639-4643.

I I7. Zahrt TC, Song J, Siple J, Deretic V: Mycobacterial FurA is a negative regulator of catalase-peroxidase gene katG. Mol Microbiol 200I, 39(5): I I74-I I85.

I I8. Ohmura N, Tsugita K, Koizumi J, Saiki H: Sulfur-binding protein of flagella of Thiobacillus ferrooxidans. J Bacteriol 1996, I 78(19):5776-5780.

119. Sand W, Gehrke T: Extracellular polymeric substances mediate bioleaching/biocorrosion via interfacial processes involving iron(III) ions and acidophilic bacteria. Res Microbiol 2006, 157(1):49-56

120. Reguera G, Pollina R, Nicoll J, Lovley D: Possible nonconductive role of Geobacter sulfurreducens pilus nanowires in biofilm formation. J Bacteriol 2007, I89(5):2/25-2। 27

I2I. Schreiner H, Sinatra K, Kaplan J, Furgang D, Kachlany S, Planet $P$, Perez B, Figurski D, Fine D: Tight-adherence genes of Actinoba- 
cillus actinomycetemcomitans are required for virulence in a rat model. Proc Natl Acad Sci USA 2003, I 00(1 2):7295-7300.

122. Rivas M, Seeger M, Holmes D, Jedlicki E: A Lux-like quorum sensing system in the extreme acidophile Acidithiobacillus ferrooxidans. Biol Res 2005, 38(2-3):283-297.

123. Rivas M, Seeger M, Jedlicki E, Holmes D: Second acyl homoserine lactone production system in the extreme acidophile Acidithiobacillus ferrooxidans. Appl Environ Microbiol 2007, 73(10):3225-323I.

124. Martin A, Yeats S, Janekovic D, Reiter WD, Aicher W, Zillig W: SAV I, a temperate u.v.-inducible DNA virus-like particle from the archaebacterium Sulfolobus acidocaldarius isolate BI2. Embo J 1984, 3(9):2165-2168.

125. Zillig W: Confusion in the assignments of Sulfolobus sequences to Sulfolobus species. Nucleic Acids Res 1993, 2 I(22):5273.

126. Barreto M, Valdes J, Dominguez C, Arriagada C, Silver S, Bueno S, Jedlicki E, Holmes D: Whole Genome Sequence of Acidithiobacillus ferrooxidans: Metabolic Reconstruction, Heavy Metal Resistance and Other Characteristics. In Biohydrometallurgy: Fundamentals, Technology and Sustainable Development: 200I Minas Gerais, Brazil: Elsevier Press; 2001:237-25I.

127. Liu Z, Guiliani N, Appia-Ayme C, Borne F, Ratouchniak J, Bonnefoy V: Construction and characterization of a recA mutant of Thiobacillus ferrooxidans by marker exchange mutagenesis. J Bacteriol 2000, I82(8):2269-2276.

128. Peng J, Yan W, Bao X: Plasmid and transposon transfer to Thiobacillus ferrooxidans. J Bacteriol 1994, I76( I0):2892-2897.

129. Siguier P, Filee J, Chandler M: Insertion sequences in prokaryotic genomes. Curr Opin Microbiol 2006, 9(5):526-53I.

130. Holmes DS, Zhao HL, Levican G, Ratouchniak J, Bonnefoy V, Varela $P$, Jedlicki $E$ : ISAfeI, an ISL3 family insertion sequence from Acidithiobacillus ferrooxidans ATCC 19859. J Bacteriol 200I, I 83( I 4):4323-4329.

13I. Oppon JC, Sarnovsky RJ, Craig NL, Rawlings DE: Tn7-like transposon is present in the gImUS region of the obligately chemoautolithotrophic bacterium Thiobacillus ferrooxidans A. J Bacteriol 1998, I 80(I I):3007-30I2.

132. Baker-Austin C, Dopson M: Life in acid: $\mathbf{p H}$ homeostasis in acidophiles. Trends Microbiol 2007, I 5(4): 165-I7I.

133. Amaro AM, Chamorro D, Seeger M, Arredondo R, Peirano I, Jerez $C A$ : Effect of external $\mathrm{pH}$ perturbations on in vivo protein synthesis by the acidophilic bacterium Thiobacillus ferrooxidans. J Bacteriol |991, 173(2):910-915.

134. Guiliani N, Jerez CA: Molecular cloning, sequencing, and expression of omp-40, the gene coding for the major outer membrane protein from the acidophilic bacterium Thiobacillus ferrooxidans. Appl Environ Microbiol 2000, 66(6):23।8-2324.

135. Venter JC, Smith HO, Hood L: A new strategy for genome sequencing. Nature 1996, 38 I:364-366.

136. Eisen JA, Nelson KE, Paulsen IT, Heidelberg JF, Wu M, Dodson RJ, Deboy R, Gwinn ML, Nelson WC, Haft DH, et al:: The complete genome sequence of Chlorobium tepidum TLS, a photosynthetic, anaerobic, green-sulfur bacterium. Proc Natl Acad Sci USA 2002, 99(14):9509-95|4.

137. Wu M, Sun LV, Vamathevan J, Riegler M, Deboy R, Brownlie JC, McGraw EA, Martin W, Esser C, Ahmadinejad N, et al.: Phylogenomics of the reproductive parasite Wolbachia pipientis wMel: a streamlined genome overrun by mobile genetic elements. PLoS Biol 2004, 2(3):E69.

138. Badger J, Olsen GJ: CRITICA: coding region identification tool invoking comparative analysis. Mol Biol Evol 1999, 16(4):512-524.

139. Delcher A, Harmon D, Kasif S, White O, Salzberg SL: Improved microbial gene identification with GLIMMER. Nucleic Acids Res 1999, 27(23):4636-464I.

140. Peterson JD, Umayam LA, Dickinson T, Hickley EK, White O: The Comprehensive Microbial Resource. Nucleic Acids Res 2001, 29(I): $123-125$.

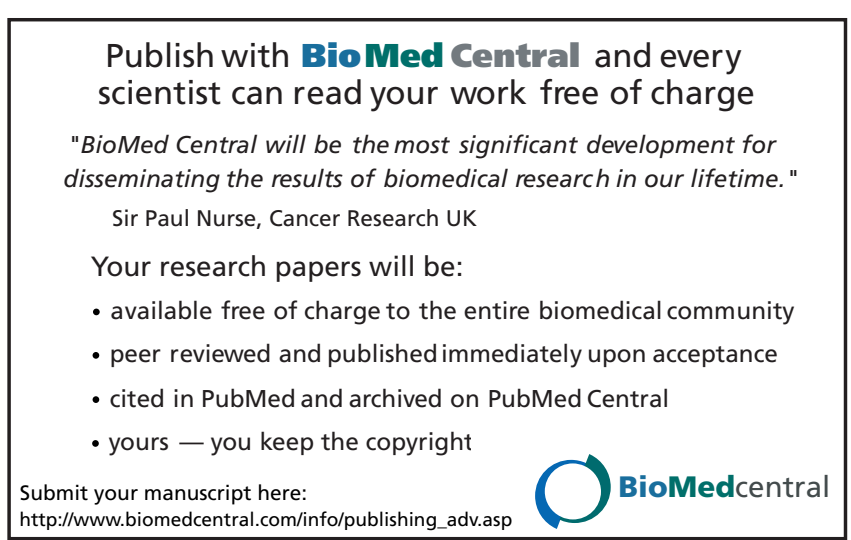

